\title{
Compositional signatures in acoustic backscatter over vegetated and unvegetated mixed sand-gravel riverbeds
}

\author{
D. Buscombe ${ }^{1}$, P.E. Grams ${ }^{2}$, and M.A. Kaplinski ${ }^{1}$
}

\footnotetext{
${ }^{1}$ School of Earth Sciences and Environmental Sustainability, Northern Arizona University, Flagstaff, AZ. USA. ${ }^{2}$ U.S. Geological Survey, Southwest Biological Science Center, Grand Canyon Monitoring \& Research Center, Flagstaff, AZ. USA.
}

Key Points:

- Co-spectra reveal coherent scales between high-resolution multibeam topography and backscatter

- Low-pass filtering backscatter removes topographic effects: resulting backscatter is better related to sediment composition

- A probabilistic framework for vegetated and unvegetated riverbed substrate classification is presented

Corresponding author: D. Buscombe, daniel buscombe@ nau .edu 


\begin{abstract}
Multibeam acoustic backscatter has considerable utility for remote characterization of spatially heterogeneous bed-sediment composition over vegetated and unvegetated riverbeds of mixed sand and gravel. However, the use of high-frequency, decimeter-resolution acoustic backscatter for sediment classification in shallow water is hampered by significant topographic contamination of the signal. In mixed sand-gravel riverbeds, changes in the abiotic composition of sediment (such as homogeneous sand to homogeneous gravel) tend to occur over larger spatial scales than is characteristic of small-scale bedform topography (ripples, dunes, bars) or biota (such as vascular plants and periphyton). A two-stage method is proposed to filter out the morphological contributions to acoustic backscatter. First, the residual supra-grainscale topographic effects in acoustic backscatter with small instantaneous insonified areas, caused by ambiguity in the local (beam-to-beam) bed-sonar geometry, are removed. Then, coherent scales between high-resolution topography and backscatter are identified using cospectra, which are used to design a frequency domain filter that decomposes backscatter into the (unwanted) high-pass component associated with bedform topography (ripples, dunes, sand waves) and vegetation, and the (desired) low-frequency component associated with the composition of sediment patches superimposed on the topography. This process strengthens relationships between backscatter and sediment composition. A probabilistic framework is presented for classifying vegetated and unvegetated substrates based on acoustic backscatter at decimeter-resolution. This capability is demonstrated using data collected from diverse settings within a $386 \mathrm{~km}$ reach of a canyon river whose bed varies among sand, gravel, cobbles, boulders, and submerged vegetation.
\end{abstract}

\title{
1 Introduction
}

Backscatter measurements collected with high-frequency (several hundred kilohertz) multibeam echo-sounders (MBES) have been used to classify and map sediment types and properties in rivers [Amiri-Simkooei et al., 2009; Eleftherakis et al., 2012; Buscombe et al., 2014a,b; Alevizos et al., 2015]. Multibeam sonar is an attractive alternative to traditional sampling (grab samples, dredges, underwater video, etc.) because it offers the potential to simultaneously map depth and classify substrate, covering large areas at high (decimeter to meter) spatial resolutions over relatively short periods of time [Guerrero and Lamberti, 2011; Wright and Kaplinski, 2011; Leyland et al., 2016].

Acoustic backscatter contains information about both the 'hardness' and 'roughness' of the insonified surface [Jackson et al., 1996]. Hardness is related to the change in acoustic impedance, and is closely related to sediment composition. Roughness is present at a range of scales, from individual grains to sediment microtopography (roughness larger than individual grains but smaller than bedforms) to larger-scale bedforms. Therefore only some roughness scales are directly related to sediment composition, the rest being related to bedforms. More well-constrained solutions to sediment classification using high-resolution (defined here as order decimeter) acoustic backscatter will require that the effects of bedform-scale roughness on backscattering is filtered out. This will improve models that relate backscattering to the continuum of substrate types based on their composition alone [Brown et al., 2011]. This is especially true of heterogeneous substrates, including those with a significant biotic component such as biofilms and extracellular polymeric substances, macroalgae, macrophytes, benthic or burrowing invertebrates, and organic detritus.

Decomposing the relative contributions of roughness and hardness to backscatter is crucial if we are to gain further insight regarding covariations between backscatter-derived metrics and particular mixes of substrate types. This is especially true for heterogeneous clastic and biogenic substrates [Kloser et al., 2010] in shallow water $(<<5 \mathrm{~m})$. In such water depths, modern high-frequency MBES can measure topography at high-resolution but not at the smallest (grain or sub-grain) scales. Insonified areas are typically much larger than individual grains, but small enough that there are relatively few numbers of independent scatterers 
per beam [Amiri-Simkooei et al., 2009]. This can allow the topographic signal in the backscatter related to the slope of the topography at the scale of the acoustic beam to overwhelm and obscure the hardness signal, thereby creating a strong topographic signature in high-resolution backscatter. Small instantaneous insonified areas or 'beams' (order decimeter to meter) also create statistical distributions of measured backscatter that violate the assumptions behind existing analytical geoacoustic models for high-frequency backscatter [Hellequin et al., 2003; Lamarche et al., 2011] which otherwise might offer a means to separate the relative contributions of roughness scales (topographic variations) and hardness. Strong residual topographic signatures in high-frequency acoustic backscatter might be compounded when morphological and/or sediment heterogeneity is such that there exists a continuum of grain sizes and/or bedform scales (ripples, dunes, bars, etc.) present whose collective distribution of amplitudes can be both above and below the wavelength of the emitted sound waves. This situation, which acoustically might be termed a mixed Rayleigh-geometric regime, will almost always be the case for high frequency acoustic systems that are typically used in shallow water and that emit sound with wavelengths of order one millimeter. Topographic signatures in acoustic backscatter therefore might impose limitations on achievable precision (i.e. the degree of discrimination among various potential substrate types) in acoustical sediment classifications.

Buscombe et al. [2014a,b] used $400 \mathrm{kHz}$ multibeam acoustic backscatter to classify a sand-dominated unvegetated mixed sand-gravel-cobble-boulder riverbed at $25 \mathrm{~cm}$ grid resolution. A three-part classification was developed for distinguishing sand from gravel from rocks and boulders, based on multiple spectral measures derived from gridded backscatter using a machine learning classifier (namely, a decision tree). The technique was tested at three sites with different hydrography and sedimentology. This study builds on that work in four main ways. First, the gridded backscatter is further processed such that the resulting signal is more strongly related to grain size, by ameliorating beam-scale topographic effects, and then using frequency domain methods to filter out the high-frequency signal content (termed 'morphological' backscatter) associated with small scale morphologies (that of topographic bedforms and/or vegetation patches). The resulting low-pass backscatter is related to both the hardness and roughness of the sediment referred to as the 'compositional' backscatter. The sediment roughness is grain-scale roughness, as well as microtopography that is smaller than the beam footprint and therefore not resolved. Second, a simpler substrate classification procedure is proposed based on a probabilistic treatment of the compositional backscatter alone, rather than multiple more complicated measures derived from unfiltered backscatter. Third, the technique is expanded to include classification of aquatic vegetation. Finally, these techniques are tested on a larger number of sites with a greater range of hydrographic and sedimentological characteristics, including aquatic vegetation, than evaluated by Buscombe et al. [2014b]. Similar to Buscombe et al. [2014b], both classifications (for unvegetated and partially vegetated beds) are developed and tested using extensive geolocated underwater video observations of the bed.

\section{Background}

\subsection{Morphological and compositional scales in unvegetated mixed sand-gravel riverbeds}

In mixed sand-gravel rivers, the sediment mixture comprising the channel bed is often sorted into discrete patches of similar grain size [e.g. Buffington and Montgomery, 1999a]. These patches can be either migrating freely or fixed in place [Nelson et al., 2009], even if a significant sediment load passes through them [Dietrich et al., 2005]. Accurately quantifying the spatial distribution, size, and persistence of sediment patches is important for understanding the distribution of in-stream bed surface microhabitats [e.g. Frissell et al., 1986; Gayraud and Philippe, 2003] as well as spawning and rearing habitats [e.g. Kondolf and Wolman, 1993; Hedger et al., 2006] with specific grain-size requirements, and for adequate specification for the roughness and sediment boundary condition in sediment transport models [e.g. Lisle et al., 2000; Ferguson, 2003]. However, this requires spatially distributed bed-sediment grain size data at high resolution [Nelson et al., 2014]. Modern high-resolution MBES offer a means to 
acquire such information in large rivers with diverse bed sedimentology and hydraulic characteristics, as well as in estuarine and coastal environments.

Most data on sediment patch sizes in mixed sand-gravel riverbeds suggest that patches are spatially more extensive than riverbed bedform topography such as ripples, dunes and small sand waves [Nelson et al., 2010, 2014, and references therein]. There is often a topographic signature, typically of low amplitude, to the sediment patches themselves, but patches tend to have larger wavelengths (i.e., decorrelation lengthscales) than superimposed bedform topography. This is generally the case for riverbed morphologies up to those scales associated with pool-riffle and braid-bar sequences, where sorted sediment patches can be smaller than those morphologies [Lisle and Madej, 1992; Buffington and Montgomery, 1999b]. In this study, we use high-resolution co-located measurements of topography and backscatter collected with MBES to calculate co-spectra that reveal coherent scales between high-resolution topography and acoustic backscatter. By harnessing the differences in decorrelation lengthscales between spatially organized sediment patches and superimposed bedform topography, frequency domain methods can be used to filter out the supra-beam-scale topographic signatures in high frequency acoustic backscatter, with the resultant backscatter related to the hardness and roughness of the sediment and individual sediment microtopographies that exist at the sub-beam-scale. This facilitates acoustical sediment classifications at an appropriate spatial resolution, which is the decorrelation lengthscale of filtered backscatter dictated by the size of the underlying sediment patch.

\subsection{Morphological and compositional scales in vegetated mixed sand-gravel riverbeds}

Submerged aquatic plants play a vital role in the dynamics of aquatic ecosystems by being an important source of food and habitat complexity in rivers, two important factors that determine density and growth of animal populations [Gregg and Rose, 1982; Bornette and Puijalon, 2011]. Given the spatial zonation of vegetation types in response to variations in water depthand quality, substrate, light, and the seasonality in growth, effectively characterizing the complexity and ecosystem function of vegetated beds is an inherently spatial problem, necessitating observations at high-resolution and with extensive coverage in both space and time. Whereas unvegetated sediment classification using MBES backscatter is common [Brown et al., 2011; Lurton and Lamarche, 2015], we are unaware of published examples of submerged vegetation detection or classification in rivers or other freshwater environments using MBES backscatter. However, there is enormous potential for such classification, and therefore mapping and temporal monitoring of submerged aquatic vegetation, if sufficiently strong relationships between backscatter and substrate can be established.

\subsection{Acoustic detection of submerged vegetation}

In marine environments, a few successful attempts have been made to detect or classify submerged aquatic vegetation using MBES. Currently, the nature of scattering by vegetation is a nascent field of study and is therefore much less well understood than for clastic substrates [Hossain et al., 2015]. Studies by Kruss et al. [2008] and Aleksandra et al. [2015] noted that dense macroalgae are weaker backscatterers than the substrates that support them, although neither of these studies used MBES backscatter to develop their respective substrate classifications. In contrast, Lyons and Abraham [1999] found that seagrasses were relatively strong scatterers compared to underlying sandy and muddy substrates, using a relatively low frequency MBES system ( $80 \mathrm{kHz})$. Data presented by De Falco et al. [2010], again using a relatively low frequency MBES system $(100 \mathrm{kHz})$, would suggest that the relative strength of seagrass backscattering is likely to be highly dependent on the density of vegetation coverage and the structure of the canopy, and also imply that such data could be used to distinguish between seagrasses and the various types of substrates that support them. Van Rein et al. [2011] found, at $300 \mathrm{kHz}$, that the MBES acoustic response of seagrass was fairly strong, but that of kelp was weak, compared to underlying substrates. McGonigle et al. [2011] showed that macrophytes could be discriminated using $400 \mathrm{kHz}$ MBES. 
Singlebeam echosounder waveform analysis (see review by Buscombe [2017]) is another common method for high-frequency acoustic substrate classification, based on analyses of the relative strength of the bed echo and its 1st multiple. A few studies have been carried out in marine environments using such analyses to discriminate between vegetated and unvegetated substrates based on their relative acoustic response [Sabol et al., 2002; Freitas et al., 2003; Quintino et al., 2009]. For example, Riegl et al. [2005] observed that the strength of second echo returns from a singlebeam sonar lay on a continuum, decreasing from bare substratum, through sparse and then dense algae, in a brackish environment. However, the acoustic signal of macrophytes was less distinct.

Collectively, previous work suggests that submerged macrophytes and adjacent abiotic substrates can be distinguished in freshwater environments using high frequency MBES backscatter. If there exists a morphological signal in such backscatter, analogous to that associated with bedform morphologies for unvegetated riverbeds, it is likely to be associated with the spacing between vegetation growing in discrete patches.

\section{Data and Methods}

\subsection{Data and Field sites}

All multibeam backscatter and bathymetric data were collected using a Teledyne-Reson ${ }^{\circledR}$ SeaBat 7125 MBES system operating at $400 \mathrm{kHz}$, with sensor attitudes provided by a vesselmounted inertial navigation system, and positions telemetered to the survey vessel at $20 \mathrm{~Hz}$ using a robotic total station situated onshore on monumented survey control points. Data are collected up to 50 pings per second, typically with a $50 \%$ overlap between adjacent sweeps. Swath sonar data collection and processing is described in Kaplinski et al. [2009, 2017] and Buscombe et al. [2014a].

The video observations of the bed were collected using a custom-built system developed in house called LOBOS (Limnological and Oceanographic Benthic Observation System, in transects at a spacing of about $20-50 \mathrm{~m}$ in the downstream direction. The system is based on an earlier system described by Rubin et al. [2007] and is built around a Sony ${ }^{\circledR}$ FCBEH6500 digital block camera, with the ability to capture high definition macro and far-field color imagery. The high-definition video system was attached to a $100 \mathrm{~m}$ armored cable on a motorized winch. Still images were collected along each transect at a spacing of about $10 \mathrm{~m}$ in the crossstream direction. Lasers spaced at $12.8 \mathrm{~cm}$ provided scale. The system has twin 700 lumen diving lights for illuminating the bed at depth, and is housed in a $45-\mathrm{kg}$ steel ball to maintain position in strong currents. At unvegetated sites downstream of the Paria, images were usable up to an average of $50 \mathrm{~cm}$ altitude above the bed, depending on turbidity, corresponding to an average field of view of $50 \times 37 \mathrm{~cm}$. Upstream at the partially vegetated site, water clarity was very high and visibility was several meters.

\subsubsection{Unvegetated mixed sand-gravel-boulder sites}

Data were collected in the Colorado River in Marble and Grand Canyons, Arizona, at river miles 30, 32, 61, 87, and 225 (approximately 48, 51, 98, 140, and $362 \mathrm{~km}$ downstream of Lees Ferry, Arizona). These sites are referred to, respectively, as RM30, RM32, RM61, RM87, and RM225 (Figure 1). The MBES and video data at RM30, RM61 and RM87 were collected during August 2013 and consist of a single survey conducted over a specific reach [Buscombe et al., 2014b]. The dataset at RM32 consists of three surveys, each survey resulting in a complete map of the entire bed in the reach, conducted within the same reach over two hours during May 2013. The dataset at RM225 consists of 88 surveys conducted within the same reach over 13 hours during July 2015. At each site, georeferenced video observations of the bed [e.g. Buscombe et al., 2014b] were made on the same day that MBES surveys were performed. . The general morphological and sedimentological characteristics of this mixed sand-gravel-boulder alluvial riverbed have been described previously [Wilson, 1986; Schmidt, 
1990; Topping et al., 2000; Hazel et al., 2006], including quantitative studies using sonar and underwater imagery [Anima et al., 2007; Grams et al., 2013; Buscombe et al., 2015]. The extent of sand on the bed varies from thick deposits supporting well-developed sand-dunes [Rubin et al., 2001], to thin sand patches that give rise to a number of 'starved' sedimentary forms [e.g. Kleinhans et al., 2002], dispersed over a coarser bed that varies among gravel, cobble, boulder and bedrock.

\subsubsection{Partially vegetated mixed sand-gravel-cobble site}

Data were collected in the Colorado River in Glen Canyon, Arizona, at river mile -4 (approximately $6.5 \mathrm{~km}$ upstream of Lees Ferry, Arizona). The site is referred to as RM-4 (Figure 1). The MBES data were collected during November 2014, and georeferenced video imagery of the bed were collected over several seasons (winter 2013, fall of 2015, and summer 2016). It was not possible to collect video imagery during the multibeam survey in November 2014, however seasonal variations in substrate types were insignificant at the resolution of the classification and did not affect the broad scale spatial distributions of those few substrate types. Significant channel adjustment in this tailwater reach, at least in recent decades, has been negligible outside of floods [Grams et al., 2007] and there were no floods between November 2014 and summer 2016. Submergent vegetation assemblage is various [Benenati et al., 1998; Shannon et al., 2001; Cross et al., 2011] and includes grasses and rushes (Phragmites australis, Vallisneria americana, Agrostis sp., Scirpus sp.), pondweed (Potamogeton filiformis, Elodea sp.), watercress (Ranunculus sp.), filamentous algae (Cladophora glomerata), Characeae (Chara sp.), and other algal taxa such as Chlorophyta (Mougeotia spp., Oedogonium spp., Spirogyra spp., Stigeoclonium spp.), Rhodophyta (Batrachospermum spp., Rhodo-chorton spp.) and Ulotrichaceae (Ulothrix zonata), cyanobacteria algalcrust (Oscillatoria spp.), aquatic moss (Didymosphenia geminata) and other bryophyta that are largely confined to deeper water. We refer to this site as 'partially vegetated' to reflect that there are portions of the bed that are unvegetated (bare substrate).

\subsection{Removing beam-scale topographic effects in high-resolution acoustic backscat- ter}

The raw backscatter amplitudes used in this study are the 32-bit 'beam amplitude' values [Schimel et al., 2015], recorded in Teledyne-Reson ${ }^{\circledR} \mathrm{s} 7 \mathrm{k}$ format, that represent the magnitude of the beam time-series at the sample closest to the bottom detection location. Backscatter data processing is further described in Buscombe et al. [2014a], in which procedures are described for correction of raw amplitudes for static gain, source level, angular response, transmission losses, and losses due to water and sediment attenuation. Time-varying gain (TVG) was not set during data acquisition because the water depths during our surveys (up to $30 \mathrm{~m}$ ) dictate that the backscatter signal will stay within the dynamic range of the instrument [Schimel et al., 2015] and because the TVG formula is not publicly available. The resultant backscatter is now more correctly termed a bed 'target strength', $T S$, which must undergo a final correction for insonified (beam) area, described below, that converts $T S$ into a backscattering strength coefficient. Appropriate modeling of the beam area allows for local (beam-scale) slope-induced topographically induced artifacts to be mitigated.

Backscatter strength coefficient, $B$, is computed per beam, per-ping, using the standard expression for scattered intensity, $I_{s}$, from the sediment interface for active sonar [e.g. Jackson and Richardson, 2007]:

$$
\left\langle I_{s}\left(R_{s}\right)\right\rangle=\frac{I_{i}}{R_{s}^{2}} A_{f} \sigma
$$

where $I_{i}$ is the incident sound intensity, $R_{s}$ is the slant-range at which the scattered intensity was measured, $A_{f}$ is the acoustic beam area, and $\sigma$ is the scattering cross section. The brackets $<>$ represent an ensemble average [Lurton and Lamarche, 2015], recognizing that bed 
scattering is an inherently stochastic process [e.g. Gavrilov and Parnum, 2010]. The target strength $(T S)$ of the bed is the relative proportion of incident energy scattered by the bed, expressed as $T S=10 \log _{10} I_{s} / I_{i}=10 \log _{10} B+10 \log _{10} A_{f}$, where $B=10 \log _{10} \sigma$ [Lurton, 2010]. This leads to the form of the active sonar equation presented by Amiri-Simkooei et al. [2009], where bottom scattering strength is given by

$$
B=10 \log _{10} \sigma=E L-C-G-S L+2 T L-A_{f}
$$

where $E L-C-G=S L-2 T L+T S, E L$ is the received amplitude corrected for angular effects (that is the inherent variability in echo level amplitude as a function of grazing angle, a procedure detailed in Buscombe et al. [2014a]), and $C$ is a calibration coefficient and takes the value $-100 \mathrm{~dB}$ for a Teledyne-Reson ${ }^{\circledR} 7125$ MBES [Welton, 2014]. During each survey, source level $S L$ and gain $G$ were held constant. Transmission loss, $T L=20 \log _{10} R_{s}+\alpha R_{s}$, where $\alpha$ is total attenuation, is computed following Buscombe et al. [2014a]. Therefore, $I_{i}=$ $S L-T L$. All terms are in decibels $(\mathrm{dB})$, or $10 \log _{10}$ of ratios between a quantity and a reference quantity of acoustic pressure of $1 \mu \mathrm{Pa}$, or $\mathrm{dB}$ with respect to $1 \mu \mathrm{Pa}$ at $1 \mathrm{~m}$. The nominal (i.e. based on a flat surface) instantaneous acoustic beam area, $A_{f}^{\prime}$, is modeled as the minimum of the pulse-length limited area (typically for outer beams) and the beam-width limited area (for near-nadir beams), or:

$$
A_{f}^{\prime}=\min \left(\frac{\omega_{t x} c \tau R_{s}}{2 \sin \psi_{i x} \cos \psi_{i y}}, \frac{\omega_{t x} \omega_{r x} R_{s}^{2}}{\cos \psi_{i x} \cos \psi_{i y}}\right)
$$

where $\omega_{t x}$ and $\omega_{r x}$ are, respectively, the transmit and receive beam widths at half power (-3 $\mathrm{dB}$ ), in radians, subscripts $x$ and $y$ refer to the along- and across-track directions, respectively, $c$ is the speed of sound in water in $\mathrm{ms}^{-1}, \tau$ is the pulse length in s, and $\psi_{x}$ and $\psi_{y}$ are the grazing angles $\left(\psi=\pi / 2-\theta\right.$ where $\theta$ is the incident angle). For Teledyne-Reson ${ }^{\circledR} 7125$ (and many other modern high frequency) systems, all these time-varying (per ping) parameters can be measured or modeled with high accuracy. Following Lanzoni and Weber [2011], who measured the transmit and receive response of the 7125 MBES system in a laboratory tank, accounting for the differences in frequencies used in that study $(200 \mathrm{kHz})$ versus the present study (400 kHz), we used $\omega_{t x}=0.99^{\circ}$ and $\omega_{r x}=2^{\circ}$.

In the above, the nominal instantaneous insonified area, $A_{f}^{\prime}$, depends only on sonar parameters (aperture, pulse duration) and sonar geometry (range, grazing angle). Grazing angles are necessarily calculated over at least three successive beams (i.e. the present and two adjacent beams), therefore for small beams the residual effects of small-scale topography can remain [Lurton and Lamarche, 2015] because the slope of the bed, as a discrete target, is no longer small compared to the beam and the pulse length. Hence the distinction between 'nominal' beam area (based on a flat bed), $A_{f}^{\prime}$ in (3), and 'true' area $A_{f}$ in (2) based on a sloping bed. Following Amiri-Simkooei et al. [2009] a scaling factor is used that relates true area to nominal area, or $A_{f}^{\prime}=\epsilon A_{f}$, which results in $\log _{10} A_{f}=\log _{10} A_{f}^{\prime}+\log _{10} \epsilon$. Equation (1) becomes:

$$
\left\langle I_{s}\left(R_{s}\right)\right\rangle=\frac{I_{i}}{R_{s}^{2}} \epsilon A_{f}^{\prime} \sigma
$$

The effect of local slope on instantaneous backscatter is therefore accounted for by $\epsilon$ which, following Amiri-Simkooei et al. [2009], is computed for each beam using

$$
-\log _{10} \epsilon=10 \log _{10}\left(\frac{\sin \left(\theta-\beta_{y}\right) \cos \beta_{x}}{\sin \theta}\right)
$$

also in $\mathrm{dB}$, where $\beta_{x}$ and $\beta_{y}$ are the local (beam-to-beam) bed slopes in the along- and acrosstrack directions, respectively, that are computed following the procedures detailed in Amiri- 
Simkooei et al. [2009] and $\theta$ is the beam incident angle. The approach taken here is to compute $B$ based on (2) and (3) for $A_{f}^{\prime}$, such that target strength is

$$
T S-\epsilon=B+A_{f}^{\prime}
$$

then resample $B, A_{f}^{\prime}$ and $\epsilon$ onto coincident regular Cartesian grids, such that $B=f(x, y)$ [cf. Buscombe et al., 2014a], and target strength becomes

$$
T S(x, y)-\epsilon(x, y)=B(x, y)+A_{f}^{\prime}(x, y)
$$

Therefore, scale factor $\epsilon(x, y)$ modifies $A_{f}^{\prime}$ to account for increasing gridded surface area due to beam-to-beam slope effects, and thereby serves to minimize the influence of edge magnitudes in gridded topography on gridded backscatter magnitudes. The epsilon correction makes up to $\mathrm{a} \pm \sim 20 \mathrm{~dB}$ change in backscatter strength, which corresponds to a change in acoustic power by up to a factor of 100. This approach improves upon that of Buscombe et al. [2014a] who used the nominal beam area $A_{f}^{\prime}$ instead of $A_{f}$, then used the Laplacian of the field of gridded backscatter values in a spline-under-tension continuous curvature interpolation to minimize spurious oscillations of backscatter values at grid boundaries, or abrupt changes in backscatter over space due to bottom topography. Here, the use of scaling $\epsilon$ allows the magnitude of the local beam-to-beam bottom slope to modify acoustic estimates of beam area (3) in order to account for the residual effects of beam-scale topography affecting the backscattering process in such a way that is consistent with the acoustic budget represented by (2).

\subsection{Spectral filtering of supra-beam-scale topographic effects in high-resolution acous- tic backscatter}

A significant co-variation between topography and backscatter, both defined over regular and coincident grids, was hypothesized to exist within a narrow range of scales associated with small amplitude bedform topography (ripples, dunes, sand waves) or inter-vegetation-patch spacing. This hypothesis was examined using cross-spectral analysis from data collected at each of the six study sites (Figure 1). Co-spectral density estimates were computed using Welch's [1967] method of ensemble averaging of multiple overlapped windows. Consistent and statistically significant peaks in ensemble coherence spectra were found to exist at all sites at wavelengths between 6 and $16 \mathrm{~m}$ (Figure 2) despite the large range in morphological and sedimentological variability of the riverbed across the five sites. The additional peak around $20 \mathrm{~m}$ wavelength at the RM61 site is due to the presence of some very large sand waves that were not present at the other sites. This introduced some topographic contamination of the compositional backscatter at the RM61 site. We could have specified a separate filter for RM61. However, we decided that for the purposes of the present study, using the same filter for all sites was preferential, because it allowed us to examine the performance of the resulting sediment classification that might be applied to all study sites. Statistical significance at the $\alpha=0.05$ level was assessed following Thompson [1979].

A low-pass filter of the backscatter spectrum preserves the low frequencies in the backscatter signal associated with sediment patches and removes the relatively high frequencies over which backscatter co-varies with riverbed bedform topography or vegetation. To reconstruct the portion of the backscatter that corresponds to the low-frequency components related to sediment composition, we performed an inverse Discrete Fourier transform on only those frequency components using a low-pass filter. To reconstruct only high-frequencies associated with bed morphology, we used a high-pass filter. The mean backscatter was subtracted from each of the gridded backscatter datasets, Discrete Fourier Transforms (DFTs) computed, and multiplied by the filter function, and inverse DFTs of the resulting product were computed, 
yielding low-pass or high-pass filtered backscatter surfaces, and the mean backscatter value is added back in.

A two-dimensional low-pass filter was constructed by specifying low $\left(f_{1}\right)$ and high $\left(f_{2}\right)$ threshold frequencies, given by

$$
F_{\text {low }}= \begin{cases}1, & f<f_{1} \\ \exp \left(\frac{-\left(f-f_{1}\right)^{2}}{2 \sigma^{2}}\right), & f \geq f_{1}\end{cases}
$$

which is a Gaussian centered on low frequency $f_{1}$, with standard deviation $\sigma=\frac{1}{3}\left|f_{2}-f_{1}\right|$ [Perron et al., 2008]. We used the inverse function to define the high-pass filter, a Gaussian centered on high frequency $f_{2}$ with the same $\sigma$ :

$$
F_{\text {high }}= \begin{cases}\exp \left(\frac{-\left(f-f_{2}\right)^{2}}{2 \sigma^{2}}\right), & f<f_{2} \\ 1, & f \geq f_{2}\end{cases}
$$

Hereafter, the low- and high-pass filtered backscatter grids are referred to as, respectively, compositional and morphological backscatter. Significant peaks in the co-spectral density at wavelengths less than $8 \mathrm{~m}$ (Figure 2) suggest that suitable values for $f_{1}$ (where the filter starts to increase appreciably above zero) and $f_{2}$ (where the filter reaches 1 ) were the spatial frequencies associated with wavelengths of, respectively, $32 \mathrm{~m}$ and $8 \mathrm{~m}$. This was found to effectively separate the morphological scales (at higher frequencies corresponding to wavelengths up to $8 \mathrm{~m}$ ) at which topography and backscatter significantly co-vary, from the (lower frequency) compositional scales where such a significant covariation is not present. The resulting filter (Figure 2) was considered universally applicable to all data collected at all six study sites, which collectively constitute a significant representation among the full spectrum of hydraulic, morphological and sedimentological characteristics of the bed of $386 \mathrm{~km}$ of the Colorado River in Glen and Grand Canyons, both partially vegetated and unvegetated.

\subsection{Classification of substrates from underwater imagery}

The video system described in section 3.1 allows a live video feed to the operator aboard a boat. The video signal is input to a computer, on which custom software, also developed in house, allows the operator to record video snippets and still frames and tag imagery with postioning data. Substrates were classified visually from the still frames. Out of a data set consisting of several thousand images, only unblurred imagery with relatively precise positions were used. Further, we used only images where the substrate could be identified unambiguously. Based on a combination of field experience, and examination of all video observations from all six study sites, there are a total of 10 unique substrate classes discernible on the riverbed within video imagery and distributions of compositional backscatter, ranging from dense vegetation to boulders and bedrock (Figure 3 and Table 1). The Folk [1954] convention of sediment facies description was adopted whereby the major constituent of mixtures was capitalized and the minor constituent was lowercase. A minor constituent was denoted if at all present (in any proportion) in the still image extracted from the video stream. Two major constituents were used if it was difficult to visually assess which was dominant. Each site downstream of the Paria river (Figure 1) is composed of sand $(S)$, sand/gravel mixtures $(S g)$, gravel $(G)$, sand/boulder/bedrock mixtures $(s B R)$ and boulder/bedrock $(b R)$ substrate types in varying proportions. Upstream of the Paria, the character of the bed is very different, consisting of patches of vegetated and unvegetated substrate. Owing to the presence of vegetation, a model was constructed with following classes: dense vegetation $(V)$, sparsely vegetated sand and gravel $(v S G)$, sparsely vegetated gravel $(v G)$, unvegetated coarse gravel/cobble mixtures $(G c)$, and unvegetated cobble/boulder/bedrock mixtures $(c B R)$. 


\subsection{Probabilistic model for sediment composition}

Compiling per-substrate frequency distributions of unfiltered (Figure 4a) and compositional (Figure 4c) backscatter over all five unvegetated study sites shows that removing the high frequencies significantly narrows the per-substrate distributions of the resulting compositional backscatter. There remains a significant degree of overlap between distributions of morphological backscatter associated with various substrates (Figure 4b). Similar patterns were observed at the partially vegetated study site (Figure 4d, e and f). For both partially vegetated and unvegetated sites, this is especially apparent for very coarse sediment (bedrock, boulders) whose spectra are particularly broad-banded [Buscombe et al., 2014a].

The greater sensitivity of compositional backscatter to substrate type compared to that of the unfiltered and morphological backscatter (Figure 4) facilitates a simpler approach to sediment classification than that taken by Buscombe et al. [2014b]. We assumed that within an overall population of compositional backscatter, there are a finite number of subpopulations, each representing a different riverbed substrate. A Gaussian mixture model (GMM) is a weighted sum of $K$ component Gaussian probability density functions with unknown parameters, given by

$$
p(\mathbf{b} \mid \lambda)=\sum_{k=1}^{K} w_{k} g\left(\mathbf{b} \mid \mu_{k}, \Sigma_{k}\right)
$$

where $\mathbf{b}$ is the compositional backscatter, $w_{k}$ are the mixture weights such that $\sum_{k=1}^{K} w_{k}=1$ and $0 \leq w_{k} \leq 1$, and $g\left(\mathbf{b} \mid \mu_{k}, \Sigma_{k}\right)$ are the $k=1: K$ component Gaussian densities, where $\lambda=\left[w_{k}, \mu_{k}, \Sigma_{k}\right], \mu_{k}$ is the mean and $\Sigma_{k}=E\left[\left(\mathbf{b}_{\mathbf{k}}-\mu_{k}\right)\left(\mathbf{b}_{\mathbf{k}}-\mu_{k}\right)^{T}\right]$ is the covariance matrix for the $k$ th component.

Parameter estimation involves iteratively estimating $\lambda=\left[w_{k}, \mu_{k}, \Sigma_{k}\right]$ and is performed using a special form of the expectation-maximization (EM) algorithm, which maximizes the likelihood of the model given the training data, consisting of a total of $N=n K$ compositional backscatter observations, $n$ for each of $K$ substrates, compiled using the compositional backscatter value within the grid cell corresponding to each video observation of each $K$ substrates. For the sequence of $K$ training vectors $\mathbf{B}=\left[\mathbf{b}_{\mathbf{k}}, \ldots, \mathbf{b}_{\mathbf{K}}\right]$,

$$
p(\mathbf{B} \mid \lambda)=\prod_{k=1}^{K} p\left(\mathbf{b}_{\mathbf{k}} \mid \lambda\right)
$$

which is solved iteratively [Dempster et al., 1977]. Beginning with an initial model $\lambda$, a new model $\lambda^{\prime}$ is estimated, updating the likelihood function such that $p\left(\mathbf{B} \mid \lambda^{\prime}\right) \geq p(\mathbf{B} \mid \lambda)$. The goal is to maximize the likelihood function with respect to $\lambda$. The $\log$ of the likelihood function is [Bishop, 2006]

$$
\ln p(\mathbf{B} \mid \lambda)=\sum_{n=1}^{N} \ln \left\{\sum_{k=1}^{K} w_{k} g\left(\mathbf{b}_{\mathbf{n}} \mid \mu_{k}, \Sigma_{k}\right)\right\}
$$

The new model then becomes the initial model for the next iteration and the process is repeated until some convergence criterion is reached. The initial model consists of the observed per-substrate mean backscatter for $\mu_{k}$, and (in lieu of better a priori information on the nature of per-substrate covariance or Gaussian function weighting) unit weight and covariance. Initial prior probabilities $w_{k}$ are equal (i.e., $\left.1 / K\right)$ ). Each compositional backscatter value is assigned to a substrate class according to the posterior probabilities for all $k$ classes. In the 'expectation' step, the current values for $\lambda$ are used to evaluate the posterior probabilities, given by 


$$
P(k \mid \mathbf{b})=\frac{w_{k} g\left(\mathbf{b}_{\mathbf{k}} \mid \mu_{k}, \Sigma_{k}\right)}{\sum_{k=1}^{K} w_{k} g\left(\mathbf{b}_{\mathbf{k}} \mid \mu_{k}, \Sigma_{k}\right)}
$$

where $w_{k}$ is the prior probability of substrate $k$ given observed $\mathbf{b}$ and $P(k \mid \mathbf{b})$ is the posterior probability. These probabilities are then used in the 'maximization' step to re-estimate $\lambda$, giving $\lambda^{\prime}=\left[w_{k}^{\prime}, \mu_{k}^{\prime}, \Sigma_{k}^{\prime}\right]$ as [Bishop, 2006]

$$
\begin{gathered}
\mu_{k}^{\prime}=\frac{1}{N_{k}} \sum_{n=1}^{N} P(k \mid \mathbf{b}) \mathbf{b}_{\mathbf{n}} \\
\Sigma_{k}^{\prime}=\frac{1}{N_{k}} \sum_{n=1}^{N} P(k \mid \mathbf{b})\left(\mathbf{b}_{\mathbf{n}}-\mu_{k}^{\prime}\right)\left(\mathbf{b}_{\mathbf{n}}-\mu_{k}^{\prime}\right)^{T} \\
w_{k}^{\prime}=N_{k} / N
\end{gathered}
$$

where $N_{k}=\sum_{N}^{n=1} P(k \mid \mathbf{b})$ is the number of points assigned to component $k$. Given new $\lambda^{\prime}$, the log likelihood (12) is evaluated. This process continues until a convergence criterion is satisfied, which in the present study was when the average gain in posterior probability from the previous iteration goes below 0.001 .

The covariance matrices in the model can be full $\left(\Sigma=\frac{1}{N-1} \sum_{n=1}^{N}\left(\mathbf{b}_{\mathbf{k}}-\mu_{k}\right)\left(\mathbf{b}_{\mathbf{k}}-\mu_{k}\right)^{T}\right)$, constrained to be diagonal $\left(\Sigma=\frac{1}{N-1} \sum_{n=1}^{N}\left(\mathbf{b}_{\mathbf{k}}-\mu_{k}\right)^{2}\right)$, or spherical $\left(\Sigma=\frac{1}{D(N-1)} \sum_{n=1}^{N} \| \mathbf{b}_{\mathbf{k}}-\right.$ $\mu_{k} \|^{2}$ ), where $D$ is the number of model parameters). Additionally, parameters can be tied among the $K$ component substrates, such as having a common covariance matrix for all substrates. To determine the optimal number of substrates and form of the covariance model, an optimization was performed using the Bayesian Information Criterion (BIC, Schwarz [1978]) as a cost function. The optimal value of each of $K$ and covariance model that collectively resulted in the lowest BIC score was used in the GMM.

\subsection{Evaluating substrate classification performance}

The underwater video bed observations were subsampled to obtain an equal number of individual locations of each substrate type. A $50 \%$ subsample of these underwater video observations, drawn at random, were then used to compile the per-substrate compositional backscatter values that were used to train the model. The remaining $50 \%$ of the underwater video observations were used to compile the per-substrate compositional backscatter values as an independent data set for testing the performance of the substrate classification model. An $F_{1}$ score was used as the evaluation measure, given by

$$
F_{1}=2 \frac{P R}{P+R}
$$

where precision, $P$, is the number of true positives in the classification divided by the sum of true and false positives, and recall, $R$, is the number of true positives divided by the sum of true positives and false negatives. The score may be interpreted as a weighted average of precision and recall, taking values between 0 and 1 .

A more conservative assessment of sediment classification performance is to examine repeat maps of the bed, from surveys separated sufficiently close in time so there are no changes to bed sediment composition through sediment transport, by calculating the degree of selftransition among the sediment classes. A self-transition is defined as when a grid cell is classified as the same substrate over two consecutive surveys. This analysis performs several 
functions. First and foremost, it permits assessment of the precision of the sediment classification, itself a function of sensitivity to small fluctuations in backscatter over time. Second, it allows for identification and quantification of preferential misclassification for given pairs of substrates. Third, it provides an objective means, independently of GMM $F_{1}$ and BIC scores, to aggregate similar substrate classes, assessed by an increase in self-transition of individual pairs of substrate classes compared to their individual or average self-transitions. Finally, it facilitates analysis of grid-size effects on substrate classification precisions, through determination of the spatial scale of aggregation that maximizes self-transitions collectively across a set of substrates.

\section{Results}

\subsection{Decomposing morphological and compositional backscatter}

Comparison of unfiltered gridded backscatter with high- (morphological) and low-pass (compositional) filtered backscatter surfaces (Figure 5) shows that the frequency domain filtering described in section 3.3 effectively decomposed the data into the two scales of interest. To illustrate this, the rocks centered at $[X=50, Y=0]$ in Figure 5a show high backscatter magnitudes in unfiltered (Figure 5b) and compositional (Figure 5d) backscatter but not in the morphological backscatter (Figure 5c) which, in turn, clearly reveals the topographic contributions to backscatter by the small amplitude field of sand dunes. Similarly, the 'streakiness' in unfiltered backscatter at the RM-4 site (Figure 5f), caused by downstream transport of relatively fine, mobile sediment by currents and their subsequent partial colonization by vegetation, is readily apparent within the compositional backscatter (Figure 5h) and weakly in the morphological backscatter signal (Figure $5 \mathrm{~g}$ ). The latter is unsurprising since the streaks themselves are small topographic mounds of a particular substrate.

\subsection{Sediment classification}

A given site, depending on whether it is upstream or downstream of the Paria river (Figure 1), is modeled using one of two mixing models, constructed for either the partially vegetated or unvegetated substrate set, respectively (described in section 3.4). The BIC score is used to evaluate how many substrates are present within a mixed population of compositional backscatter observations, but experience and knowledge of the physical environment, and the quality and number of ground truth observations, informs how to combine similar classes because some are infrequent or indistinguishable. For example, if there are too few video ground-truth observations of a particular substrate to form a statistically meaningful distribution of associated compositional backscatter, or otherwise if two substrates are physically (and therefore acoustically) so similar that their distributions of associated compositional backscatter are indistinguishable.

Of the study sites, only RM -4 has significant amounts of submerged vegetation. Two GMM models were constructed, one for partially vegetated and another for unvegetated sites. The minimum BIC for unvegetated substrate models was determined to be associated with six components and the full covariance matrix. The 6-substrate estimated decision surface is presented in Figure 6a, showing the probability of each class given a compositional backscatter value, over the full range of the parameter space. Since only five of the nine substrate classes are represented among the five study sites on which this model is based, the model necessarily includes a tenth 'unknown' substrate class (Table 1). Given its generally high backscatter, physically it is thought to represent the tail of backscatter associated with boulders and bedrock $(b R)$, so $U$ and $b R$ are combined into one class. In addition, $b R$ and $s B R$ (sand/boulder/bedrock) may be combined because the dominant controls on backscattering are the boulders/bedrock, not the sand. Therefore, a single class is used to represent all very coarse sediment mixtures of sand, boulders and bedrock that are dominated by the latter two, and the total number of classes in the final classification, for which $F_{1}$ scores are computed, is four (namely, $S, S g, G$, and $s B R$ : Table 1). The confusion matrices compiled from the results 
of each model reveal that when a given substrate is misclassified, this is almost always as the substrate next highest in average compositional backscatter magnitude (Table 2).

For the partially vegetated substrate model, the minimum BIC was determined to be associated with five components and the full covariance matrix (Figure 6b). In the final classification, sparsely vegetated gravel $(v G)$ and unvegetated coarse gravel $(G c)$ were combined into one class, because of the physical similarity between $v G$ and $G c$. The very large covariance for the $G c$ class (Table 1) provides an indication more of the sedimentological variability within this group than any unexplained unresponsiveness of compositional backscatter to this substrate. The same can be said for the the $S B R$ class, which also has a large covariance. A large covariance for a given class probably indicates that it is too broad a discrete category for the range of compositional backscatter magnitudes it represents. The classes $s B R$ and $G c$ can therefore be thought of as the 'sink' components in their respective models, since there is every indication that compositional backscatter might covary with grain size continuously, and that our ability to define, acoustically, the discrete boundaries between adjacent substrates is imperfect.

The substrate classification is exemplified by the unvegetated RM 30 site (Figure 7) and partially vegetated RM -4 site (Figure 8 ) which capture the observed patterns in the substrates as gleaned from the geolocated video observations, as well as revealing the fine-scale details of patch sizes and patterns that would be impractical to capture with any other type of discrete sampling method. One particular advantage of using GMM models for substrate classification is the utility of computed posterior probabilities for each substrate class, per compositional backscatter value, for evaluation of per-grid-cell uncertainty and any spatial patterns therein (Figure 9). The first-order control on these spatial patterns of uncertainty is relative proximity to dissimilar sediment (i.e. a different substrate class), such that probabilities for a given substrate are higher toward the center of a patch of that substrate, which might be understood mechanistically in terms of hydraulic controls on bedforms, grain size, and/or sediment patch size.

Out-of-sample classification performance of the unvegetated model was assessed using $F_{1}$ scores, using the remaining $50 \%$ of geolocated video observations aggregated across all five study sites that weren't used to construct the GMM model. These scores ranged between 0.91 and 1.00 for the four unvegetated substrate classes (Table 1). Similar to the findings of Buscombe et al. [2014b], classification performance is higher for sedimentary end members (sand and boulder) than for gravel and other mixtures composed of intermediate grain sizes (sand and gravel). A similar evaluation of the classification performance for the vegetated substrate model revealed scores of between 0.7 and 0.99 (Table 1) with the highest predictive performance for dense vegetation and sparsely vegetated fines.

\subsection{Precision of unvegetated sediment classification at various grid resolutions}

Suitable data for an analysis of self-transition were available to test only the unvegetated substrate classification, using repeat survey data from the RM 32 and RM 225 sites. At RM 32, substrate maps were developed from three surveys over the course of 2 hours. At RM 225, 88 substrate maps were developed from surveys conducted over 13 hours, allowing evaluation of 44 sets of per-pixel sediment transitions over single time steps (average time between surveys was less than 10 minutes). Each substrate map from RM 225 was constructed from backscatter on a regular $10 \mathrm{~cm}$ grid. Each substrate map from the RM 32 site was constructed from backscatter gridded at various resolutions, from $10 \mathrm{~cm}$ to $12 \mathrm{~m}$ individual pixels.

Reach-aggregated areal percentages of each class at RM 32 changed less than $2 \%$, over the course of the three surveys, for each of the four substrate classes, $S, S g, G$, and $s B R$ (Figure 10b-d). Self-transitions at the $10 \mathrm{~cm}$ grid scale (Figure 11a - b) showed that sand classifications are relatively high in precision (82 and $89 \%$ self-transition, respectively, for the two pairs of surveys). The self-transitions were significantly lower for $S g$ (57 and $60 \%$ self-transition, or alternatively stated, a 43 and $40 \%$ degree of imprecision) and $G$ (67 and 69 
$\%$ self-transition, or 33 and $31 \%$ degree of imprecision). At successively larger grid sizes, the degree of self-transition increased for all substrates up to a grid size of $4.8 \mathrm{~m}$ (Figure 11, right panels), after which further increases in self-transition were not observed (and therefore not shown). At a grid resolution of $4.8 \mathrm{~m}$, the degree of imprecision had reduced to, respectively, $9,35,26$ and $14 \%$ for the four substrate classes.

A similar analysis at the RM 225 site (Figure 12), based on the same 4 classes ( $S, S g$, $G$, and $s B R$ ), showed that there was up to a $3 \%$ variation in per-substrate, reach-averaged area over the course of 13 hours (Figure 12a). This suggests that the acoustical sediment classification method is precise enough to reliably detect actual changes in substrate composition over time that are greater than about $3 \%$. Like at RM 32, there was a relatively high precision for $S$ (large sand-sand transitions, Figure 12d). Such analyses can be used in an operational sense to assess the precisions of individual substrate classes and therefore the need, or otherwise, to combine/reduce the number of invidual discrete classes. For example, at RM 225 a combined class of $s B R$ (sand/boulder/bedrock) shows a higher degree of precision ( $83 \%$ self-transition, Figure 12d) than their individual probabilities of self-transition.

\section{Discussion}

In mixed sand-gravel-bedded rivers, that are vegetated to varying degrees, the collection and analysis of high-resolution, high-frequency bathymetric and backscatter data using a MBES can be used to construct spatially explicit substrate classification maps at order decimeter grid resolution. This type of data product can be produced by filtering out the morphological signal within gridded backscatter, and using the resulting 'compositional' backscatter within a probabilistic framework that can be calibrated to individual sites or groups of riverbeds with similar sedimentological and morphological character. The model parameters can be updated easily when more or better ground-truth information (such as geolocated video observations of the bed) becomes available.

The techniques outlined in this paper facilitate the use of time-series of backscatter maps to construct substrate maps that can help to reveal the dynamics of heterogeneous sedimentary systems in a range of aquatic environments. This type of analysis now can be carried out at a sufficiently small resolution for revealing the dynamics of small sediment patches and bedforms, and at a sufficiently large coverage that resulting insights may be analyzed with respect to spatially averaged flow fields and gradients in sediment transport flux. A change detection threshold of around $3 \%$ for various clastic substrates (Figure 12a) implies that acoustical substrate classifications such as those presented here provide the means to analyze the dynamics of sand patches on gravel riverbeds at a hitherto unprecedented resolution. Such precision should allow measurements of the extent to which some sand patches grow in place as a result of changing sediment supply [Dietrich et al., 2005; Nelson et al., 2009], and how those fixed patches are distributed in space. This would significantly contribute to continuing efforts to uncover the role of bed surface particle size patchiness in bedload transport and morphological response to changes in sediment supply in mixed sand-gravel-bed rivers, as well as how these dynamics affect streambed microhabitats and organisms that use the bed for spawning and rearing.

While classification performance can be assessed statistically, it is ultimately contextdependent for discrete substrates whose individual importance varies depending on the scientific or management question the substrate map is used to address. For example, the present models performed best for, respectively, sand and dense vegetation. Fortuitously, these are the submerged substrates that are the principal object of management interest within Glen and Grand Canyons [Cross et al., 2011; Melis et al., 2012, 2015]. In Glen Canyon, understanding what controls the density and growth of trout is important for managing the tailwater fishery [Melis et al., 2015] and this is strongly linked to the changing composition of submerged aquatic vegetation populations due to the spread of non-native plant species since the early 1990s [Blinn et al., 1998]. In Grand Canyon, the sand resource is of management interest 
principally because windblown sand protects upland archaeological resources [Draut, 2012], and because sandbars are used as campsites by river recreationists [Kearsley et al., 1994].

The smaller accuracy (Table 1) and larger imprecision (Figures 11 and 12) for $G$ (gravel) and $S g$ (sand/gravel mixtures) within the present model would mean their temporal dynamics would be more difficult to elucidate. There are a number of potential avenues that might be explored to extract further substrate information from high-frequency backscatter and achieve better discrimination among many more substrate classes, or even characteristics of sediment that lie on a continuum (such as grain size). In the present study, the backscatter data used was the beam amplitude closest to the bottom detection location. However, many modern MBES systems also record the time-series of backscatter from within individual acoustic beams, socalled 'snippets' or beam area time-series [Schimel et al., 2015]. In shallow water, these individual series will be short in duration owing to very small beams, however there might be further compositional information to be gleaned even within these short data series. Time-series of backscatter data collected through the water column [Best et al., 2010] might be particularly effective for characterizing submerged vegetation [McGonigle et al., 2011], especially tall leafy aquatic plants such as kelp, seagrasses, and certain other macrophytes whose vertical structure might be imaged and quantified as well as their areal extents. Finally, technological developments in multi-frequency multibeam sonar that survey simultaneously at multiple acoustic frequencies are currently at various stages of research and development, but promise to open up new possibilities in acoustical remote sensing by increasing the discriminatory power of backscatter for substrate classification [Beaudoin et al., 2016] in much the same way that multispectral sensors have facilitated advanced automated landcover classifications from satellite data.

Gaussian mixture models have been used previously by Simons and Snellen [2009] and Alevizos et al. [2015] for seafloor and riverbed classification using specific subsets of unfiltered, ungridded backscatter data (only the backscatter collected at a certain grazing angle). A somewhat more complicated Bayesian approach was adopted by those studies to model the number of Gaussians in the mixture, and their parameters. The principal potential advantage of such an approach is a more robust estimate of the most likely number of Gaussians in the mixture [Bishop, 2006]. In this study, the Bayesian approach to GMM parameter estimation was also tried, but did not result in better classification accuracy, therefore the simpler non-Bayesian approach was adopted. The Bayesian approach might be preferable if the nonBayesian approach is not viable, which may be true in at least the following situations: 1) if unfiltered backscatter is used instead of compositional backscatter, or when ground-truth data is sparse or unreliable so an estimate of the number of unique substrates is poorly constrained; 2) Bayesian analyses might provide a fully objective means to assess the optimal combination (or partition) of sets of discrete substrate classes, rather than the partially subjective approach taken here based on field experience, evaluation of BIC scores, and analysis of transition probabilities; 3) the Bayesian approach might be preferable for modeling the composition of substrates with very different sedimentary or biological characteristics or components than those examined here.

An insight into why the frequency domain filtering is such an effective tool for enhancing the discriminatory power of backscatter among various substrates is provided by examining and comparing the decorrelation length scales (related to the lag of the first zero crossing of the spatial autocorrelation function) of unfiltered and filtered backscatter. We computed the decorrelation length scales of topography from extracted transects over known substrate types, and were found to consistently vary inversely with grain size (Figure 13e). This is because smaller grain sizes such as sand tend to occur in larger area patches. This relationship should also be present in the unfiltered backscatter but it is not (compare the sequence of markers with increasing wavelength in Figure 13e and Figure 13f) because of high frequency topographic contamination in the signal. However, it is restored for compositional backscatter (Figure $13 \mathrm{~g}$ ) which suggests that the topographic contamination has been successfully filtered out. The wavelengths associated with decorrelation for compositional backscatter are in the range 
of three to five meters, which is approximately the same grid scale at which self-transition probabilities are highest when examining time-series of substrate classifications (Figure 11). This result therefore further implies that autocorrelation analyses of compositional backscatter from a single survey might be useful for determining the appropriate scale for substrate classifications, perhaps even on a site-by-site basis, when per-substrate transition probabilities are not available. Since compositional backscatter is composed of fluctuations at relatively large spatial wavelengths (Figure 5), autocorrelation analyses also provide a clue for why there are generally higher precisions for sand classifications, as revealed by the self-transition analyses (Figures 11 and 12d). We posit that the high precision of sand is due to the relatively small average distance of a sand grid cell to another sand grid cell, which is small because sand patches tend to be large (hence the larger decorrelation lengthscales), whereas coarser substrates exist in smaller, more spatially isolated patches (Figures 9, 10, and 12).

Similar to the findings of Buscombe et al. [2014b], both models in the present study perform worse for unvegetated gravel than for sand. A potential reason is that, acoustically, a sand-gravel-cobble dominated riverbed is a mixed Rayleigh-geometric regime. This is because the range of grain roughness scales (sub-millimeter to meter) straddle the acoustic wavelength (3.68 mm for a $400 \mathrm{kHz}$ system in freshwater with a speed of sound of $1475 \mathrm{~ms}^{-1}$ ). In the present study, compositional backscatter is not contaminated with the scattering signal associated with bedform-scale topography but is still potentially affected by roughness associated with microtopographies. However, assuming such microtopography is not present, acoustic scattering theory allows us to relate uniform grain sizes to elemental scattering regimes based on acoustic wavelength. For a $400 \mathrm{kHz}$ system in fresh water with a speed of sound of 1475 $\mathrm{ms}^{-1}$, this theory would suggest that the range of grain sizes for gravels and cobbles almost coincide with the boundaries between Rayleigh and geometric scattering at, respectively, the lower and upper end (Figure 14). The variation in the scattering cross section form function (Figure 14) in this transition region translates to a greater variation in compositional backscattering strength. This acoustical variation is independent of topography, being simply the transition zone between where scattering is due to roughness elements smaller than the wavelength of sound, in the Rayleigh regime, and the zone where scattered sound intensity is proportional to the insonified surface area, in the geometric regime [Medwin and Clay, 1998]. The implication is that a different acoustic frequency is required that ensures gravel is not in the transition regime. When the speed of sound in water is $1475 \mathrm{~ms}^{-1}$, the highest frequency where all gravel surfaces scatter within the Rayleigh regime is $25 \mathrm{kHz}$. However, surveying at this low frequency would significantly increase the beam width and therefore significantly lower the achievable bathymetric resolution. This is therefore potentially a fundamental limitation to classification of gravels based on backscatter alone at common frequencies for mapping in shallow water, and a future extension of the present method could combine acoustical and topographic roughness metrics [e.g. Brasington et al., 2012; Buscombe, 2016] or backscatter response at multiple acoustic frequencies [Beaudoin et al., 2016] for better classification of the gravel fractions. Finally, whereas this study has focused on the substrate information within compositional backscatter, the information within the morphological component of backscatter could potentially open a new avenue of fundamental enquiry into the nature of acoustic backscattering by surfaces based on their form roughness alone, independent of grain-size. Isolating backscatter at certain wavelengths of the underlying topography using frequencydomain filtering would allow better separation of the relative contributions to backscattering of form and grain roughness, hardness (acoustic impedance), and other geoacoustic properties. In turn, this might help better constrain the deterministic description of high-frequency backscatter in shallow water where small beam areas promote statistical variability due to insufficient numbers of independent scatterers.

\section{Summary}

Observations of high frequency (several hundred $\mathrm{kHz}$ ), high resolution (decimeter) multibeam backscatter can be used to classify substrates in terms of composition, but this approach 
can be made considerably more effective if the significant contamination of backscatter by topography is mitigated. In rivers with spatially heterogeneous beds composed of vegetated and unvegetated mixed sand and gravel, significant changes in the abiotic component of sediment composition (such as homogeneous sand to homogeneous gravel) tend to occur over larger spatial scales than caused by small-scale bedform topography such as ripples and dunes or biota (principally vascular plants and periphyton). This observation is used in conjunction with cross-spectral analysis of coincident topography and backscatter to design a filter to remove these morphological contributions to backscatter. The resulting filtered, or 'compositional', backscatter is more strongly related to the substrate composition of the bed.

First, the residual supra-grain-scale topographic effects in backscatter with small instantaneous insonified areas are removed. Such topographic contamination of the compositional (grain size) signature within high-frequency, high-resolution multibeam acoustic backscatter, caused by ambiguity in the beam-to-beam bed-sonar geometry due to local slopes, is to be expected in any shallow water situation where beam areas are small compared to bed topography and vegetation patch scales. Then, a frequency domain filter is used to decompose backscatter into two components, the high-pass component associated with bedform topography (ripples, dunes, bars) or vegetation that is not strongly associated with sediment composition, and the low-pass component that is strongly associated with the composition of superimposed sediment patches. Statistically significant coherent scales between high-resolution topography and backscatter were identified using co-spectra. The form of this covariation was very similar across six study sites from diverse settings that collectively encompass a large range of hydrographic and sedimentological variability within a $386 \mathrm{~km}$ reach of a canyon river whose bed varies among sand, gravel, cobbles, boulders and differing areal densities of submerged vegetation. Therefore, the same frequency-domain filter could be applied to all sites. Establishing the generality of the form of topographic-backscatter co-spectra should be the focus of future research efforts.

The frequency domain filtering results in considerably stronger relationships between the resulting 'compositional' backscatter and sediment composition. In turn, this greatly facilitates the use of a probabilistic approach to classification of heterogeneous sediment at decimeter-resolution, based on high-frequency compositional backscatter alone. The approach should be highly transferable to remotely characterizing the sediment composition of other rough, heterogeneous beds in shallow water, both freshwater and marine, where highresolution backscatter is hampered by morphological contamination of the signal .

The probabilistic model was shown to be a parsimonious, powerful and potentially general approach to substrate classification. $F_{1}$ scores (a weighted average of precision and recall) based on out-of-sample validations revealed that classifications for individual substrates are accurate to within 70 to $100 \%$. An analysis of transition probabilities of classified substrates based on maps constructed from time-series of compositional backscatter from repeat surveys at two sites revealed that sand-dominated substrates had a greater degree of precision than gravel- and rock-dominated substrates, and that accuracy and precision were not necessarily well correlated. Similar analyses carried out by successively aggregating grid sizes show that precisions of all substrate classes improved up to a scale of $\sim 5 \mathrm{~m}$ (approaching the lower filter wavelength used to filter out the morphological signal within the backscatter), at which precisions were within 65 and $91 \%$ depending on the substrate. These analyses of transitions also suggested that the acoustical sediment classification method is precise enough to reliably detect actual areal changes in bed sand composition over time that are greater than about $3 \%$, which has significant implications for revealing the dynamics of sorted bedforms and sedimentary patches at a range of scales and in a range of aquatic environments, both freshwater and marine.

\section{Acknowledgments}

This work was funded by the Glen Canyon Dam Adaptive Management Program administered by the U.S. Bureau of Reclamation. Any use of trade, product, or firm names is for 
descriptive purposes only and does not imply endorsement by the U.S. government. The data analyzed and discussed in this manuscript were collected by the dedicated efforts of many field technicians, river guides, and volunteers. Special thanks to Bob Tusso and Gerry Hatcher for building the underwater video camera systems used in this study, and to Mike Yard, Ted Melis and Bob Tusso for their help with collecting video observations of the bed. The suggestions of the Editor, Carl Legleiter and two anonymous reviewers significantly improved the manuscript. All data and computer code for implementing the methods herein are available at https://doi.org/10.5066/F7B56HM0 [Buscombe et al., 2017].

\section{References}

Aleksandra, K., Fantina, M., Marco, S., Ferrarin, C., and Giacomo, M. G. (2015). Assessment of submerged aquatic vegetation abundance using multibeam sonar in very shallow and dynamic environment. The Lagoon of Venice (Italy) case study. In Acoustics in Underwater Geosciences Symposium (RIO Acoustics), 2015 IEEE/OES, pages 1-7.

Alevizos, E., Snellen, M., Simons, D. G., Siemes, K., and Greinert, J. (2015). Acoustic discrimination of relatively homogeneous fine sediments using Bayesian classification on MBES data. Marine Geology, 370:31-42.

Amiri-Simkooei, A., Snellen, M., and Simons, D. G. (2009). Riverbed sediment classification using multi-beam echo-sounder backscatter data. Journal of the Acoustical Society of America, 126:1724-1738.

Anima, R., Wong, F. L., Hogg, D., and Galanis, P. (2007). Side-scan sonar imaging of the Colorado River, Grand Canyon. U.S. Geological Survey Open-File Report 2007-1216, 15 p.

Beaudoin, J., Hughes Clarke, J., Doucet, M., Brown, C., Brissette, M., and Gazzola, V. (2016). Setting the stage for multi-spectral acoustic backscatter research. GeoHab 2016, Winchester UK, May 3-5, 2016.

Benenati, P. L., Shannon, J. P., and Blinn, D. W. (1998). Desiccation and recolonization of phytobenthos in a regulated desert river: Colorado River at Lees Ferry, Arizona, USA. Regulated Rivers: Research \& Management, 14(6):519-532.

Best, J., Simmons, S., Parsons, D., Oberg, K., Czuba, J., and Malzone, C. (2010). A new methodology for the quantitative visualization of coherent flow structures in alluvial channels using multibeam echo-sounding (MBES). Geophysical Research Letters, 37(6).

Bishop, C. M. (2006). Pattern recognition and machine learning. Springer Science \& Business Media. 738 pp.

Blinn, D. W., and Shannon, J. P., and Benenati, P. L. and Wilson, K. P. (1998). Algal ecology in tailwater stream communities: the Colorado River below Glen Canyon Dam, Arizona. Journal of Phycology, 34(5):734-740.

Bornette, G. and Puijalon, S. (2011). Response of aquatic plants to abiotic factors: a review. Aquatic Sciences, 73(1):1-14.

Brasington, J., Vericat, D., and Rychkov, I. (2012). Modeling river bed morphology, roughness, and surface sedimentology using high resolution terrestrial laser scanning. Water Resources Research, 48:W11519.

Brown, C. J., Smith, S. J., Lawton, P., and Anderson, J. T. (2011). Benthic habitat mapping: A review of progress towards improved understanding of the spatial ecology of the seafloor using acoustic techniques. Estuarine, Coastal and Shelf Science, 92:502-520.

Buffington, J. M. and Montgomery, D. R. (1999a). A procedure for classifying textural facies in gravel-bed rivers. Water Resources Research, 35:1903-1914.

Buffington, J. M. and Montgomery, D. R. (1999b). Effects of hydraulic roughness on surface textures of gravel-bed rivers. Water Resources Research, 35:3507-3522.

Buscombe, D. (2016). Spatially explicit spectral analysis of point clouds and geospatial data. Computers \& Geosciences, 86:92-108.

Buscombe, D. (2017). Shallow water benthic imaging and substrate characterization using recreational-grade sidescan-sonar. Environmental Modelling \& Software, 89:1-18. 
Buscombe, D., Grams, P. E., and Kaplinski, M. A. (2014a). Characterizing riverbed sediments using high-frequency acoustics 1: Spectral properties of scattering. Journal of Geophysical Research - Earth Surface, 119:doi:10.1002/2014JF003189.

Buscombe, D., Grams, P. E., and Kaplinski, M. A. (2014b). Characterizing riverbed sediments using high-frequency acoustics 2: Scattering signatures of Colorado River bed sediments in Marble and Grand Canyons. Journal of Geophysical Research - Earth Surface, 119:doi:10.1002/2014JF003191.

Buscombe, D., Grams, P. E., and Smith, S. M. (2015). Automated riverbed sediment classification using low-cost sidescan sonar. Journal of Hydraulic Engineering, pages 06015019, doi:10.1061/(ASCE)HY.1943-7900.0001079.

Buscombe, D., Grams, P. E., and Kaplinski, M. A. (2017). Acoustic backscatter - Data and Python code. U.S. Geological Survey data release, https://doi.org/10.5066/F7B56HM0.

Cross, W. F., Baxter, C. V., Donner, K. C., Rosi-Marshall, E. J., Kennedy, T. A., Hall, R. O., Kelly, H. A. W., and Rogers, R. S. (2011). Ecosystem ecology meets adaptive management: food web response to a controlled flood on the Colorado River, Glen Canyon. Ecological Applications, 21(6):2016-2033.

De Falco, G., Tonielli, R., Di Martino, G., Innangi, S., Simeone, S., and Parnum, I. M. (2010). Relationships between multibeam backscatter, sediment grain size and Posidonia oceanica seagrass distribution. Continental Shelf Research, 30(18):1941-1950.

Dempster, A. P., Laird, N. M., and Rubin, D. B. (1977). Maximum likelihood from incomplete data via the EM algorithm. Journal of the Royal Statistical Society. Series B (Methodological), pages $1-38$.

Dietrich, W., Nelson, P., Yager, E., Venditti, J., and Lamb, M. (2005). Sediment patches, sediment supply, and channel morphology. River, Coastal and Estuarine Morphodynamics, pages 79-90.

Draut, A. E. (2012). Effects of river regulation on aeolian landscapes, Colorado River, southwestern USA. Journal of Geophysical Research: Earth Surface, 117:F02022.

Eleftherakis, D., Amiri-Simkooei, A., Snellen, M., and Simons., D. G. (2012). Improving riverbed sediment classification using backscatter and depth residual features of multi-beam echo-sounder systems. Journal of the Acoustical Society of America, 131:3710-3725.

Ferguson, R. (2003). The missing dimension: effects of lateral variation on 1-D calculations of fluvial bedload transport. Geomorphology, 56(1):1-14.

Folk, R. L. (1954). The distinction between grain size and mineral composition in sedimentary-rock nomenclature. Journal of Geology, 62:345-359.

Freitas, R., Rodrigues, A. M., and Quintino, V. (2003). Benthic biotopes remote sensing using acoustics. Journal of Experimental Marine Biology and Ecology, 285:339-353.

Frissell, C. A., Liss, W. J., Warren, C. E., and Hurley, M. D. (1986). A hierarchical framework for stream habitat classification: viewing streams in a watershed context. Environmental Management, 10(2):199-214.

Gavrilov, A. N. and Parnum, I. M. (2010). Fluctuations of seafloor backscatter data from multibeam sonar systems. IEEE Journal of Oceanic Engineering, 35(2):209-219.

Gayraud, S. and Philippe, M. (2003). Influence of bed-sediment features on the interstitial habitat available for macroinvertebrates in 15 French streams. International Review of $\mathrm{Hy}$ drobiology, 88(1):77-93.

Grams, P. E., Schmidt, J. C., and Topping, D. J. (2007). The rate and pattern of bed incision and bank adjustment on the Colorado River in Glen Canyon downstream from Glen Canyon Dam, 1956-2000. Geological Society of America Bulletin, 119:556-575.

Grams, P. E., Topping, D. J., Schmidt, J. C., Hazel, J. E., and Kaplinski, M. (2013). Linking morphodynamic response with sediment mass balance on the Colorado River in Marble Canyon: Issues of scale, geomorphic setting, and sampling design. Journal of Geophysical Research - Earth Surface, 118:361-381.

Gregg, W. W. and Rose, F. L. (1982). The effects of aquatic macrophytes on the stream microenvironment. Aquatic Botany, 14:309-324. 
Guerrero, M. and Lamberti, A. (2011). Flow field and morphology mapping using ADCP and multibeam techniques: Survey in the Po River. Journal of Hydraulic Engineering, 137:1576-1587.

Hazel, J. E., Topping, D. J., Schmidt, J. C., and Kaplinski, M. (2006). Influence of a dam on fine-sediment storage in a canyon river. Journal of Geophysical Research: Earth Surface, 111(F1).

Hedger, R., Dodson, J., Bourque, J., Bergeron, N., and Carbonneau, P. (2006). Improving models of juvenile atlantic salmon habitat use through high resolution remote sensing. Ecological Modelling, 197(3):505-511.

Hellequin, L., Boucher, J. M., and Lurton, X. (2003). Processing of high-frequency multibeam echo sounder data for seafloor characterization. IEEE Journal of Oceanic Engineering, 28:78-89.

Hossain, M., Bujang, J. S., Zakaria, M., and Hashim, M. (2015). The application of remote sensing to seagrass ecosystems: an overview and future research prospects. International Journal of Remote Sensing, 36(1):61-114.

Jackson, D. and Richardson, M. (2007). High-frequency seafloor acoustics. Springer Science \& Business Media. 615 pp.

Jackson, D. R., Briggs, K. B., Williams, K. L., and Richardson, M. D. (1996). Tests of models for high-frequency seafloor backscatter. IEEE Journal of Oceanic Engineering, 21:458470.

Kaplinski, M., Hazel, J., Grams, P., Kohl, K., Buscombe, D., and Tusso, R. (2017). Channel mapping river miles 2962 of the Colorado River in Grand Canyon National Park, Arizona, May 2009. U.S. Geological Survey Open-File Report, 2017-1030:41 pp.

Kaplinski, M., Hazel, J. E., Parnell, R., Breedlove, M., Kohl, K., and Gonzales, M. (2009). Monitoring fine-sediment volume in the Colorado River Ecosystem, Arizona: Bathymetric survey techniques. U.S. Geological Survey Open-file Report, 2009-1207:41 pp.

Kearsley, L. H., and Schmidt, J. C. and Warren, K. D. (1994). Effects of Glen Canyon dam on Colorado River sand deposits used as campsites in Grand Canyon National Park, USA. River Research and Applications, 9:137-149.

Kleinhans, M. G., Wilbers, A. W., De Swaaf, A., and Van Den Berg, K. H. (2002). Sediment supply-limited bedforms in sand-gravel bed rivers. Journal of Sedimentary Research, 72:629-640.

Kloser, R. J., Penrose, J. D., and Butler, A. J. (2010). Multi-beam backscatter measurements used to infer seabed habitats. Continental Shelf Research, 30:1772-1782.

Kondolf, G. M. and Wolman, M. G. (1993). The sizes of salmonid spawning gravels. Water Resources Research, 29(7):2275-2285.

Kruss, A., Blondel, P., Tegowski, J., Wiktor, J., and Tatarek, A. (2008). Estimation of macrophytes using single-beam and multibeam echosounding for environmental monitoring of Arctic fjords (Kongsfjord, West Svalbard Island). Journal of the Acoustical Society of America, 123(5):3213-3213.

Lamarche, G., Lurton, X., Verdier, A.-L., and Augustin, J.-M. (2011). Quantitative characterisation of seafloor substrate and bedforms using advanced processing of multibeam backscatter - Application to Cook Strait, New Zealand. Continental Shelf Research, 31:93109.

Lanzoni, J. and Weber, T. (2011). A method for field calibration of a multibeam echo sounder. In OCEANS 2011, pages 1-7.

Leyland, J., Hackney, C. R., Darby, S. E., Parsons, D. R., Best, J. L., Nicholas, A. P., Aalto, R., and Lague, D. (2016). Extreme flood-driven fluvial bank erosion and sediment loads: direct process measurements using integrated Mobile Laser Scanning (MLS) and hydro-acoustic techniques. Earth Surface Processes and Landforms, 42:334346.

Lisle, T. E., and Madej, M. A. (1992). Spatial variation in armouring in a channel with high sediment supply. In: Dynamics of Gravel-bed Rivers, edited by P. Billi, R. D. Hey, C. R. Thorne and P. Tacconi, pp. 277-293, Wiley, New York. 
Lisle, T. E., Nelson, J. M., Pitlick, J., Madej, M. A., and Barkett, B. L. (2000). Variability of bed mobility in natural, gravel-bed channels and adjustments to sediment load at local and reach scales. Water Resources Research, 36(12):3743-3755.

Lurton, X. (2010). An Introduction to Underwater Acoustics, 2nd edition. Springer, Heidelberg. 349 pp.

Lurton, X. and Lamarche, G. (2015). Backscatter measurements by seafloor-mapping sonars. Marine Geological and Biological Habitat Mapping. A collective report by members of the GeoHab Backscatter Working Group, 200 pp.

Lyons, A. P. and Abraham, D. A. (1999). Statistical characterization of high-frequency shallow-water seafloor backscatter. The Journal of the Acoustical Society of America, 106(3):1307-1315.

McGonigle, C., Grabowski, J. H., Brown, C. J., Weber, T. C., and Quinn, R. (2011). Detection of deep water benthic macroalgae using image-based classification techniques on multibeam backscatter at Cashes Ledge, Gulf of Maine, USA. Estuarine, Coastal and Shelf Science, 91(1):87-101.

Medwin, H. and Clay, C. S. (1998). Fundamentals of Acoustical Oceanography. Academic Press, London. 717 pp.

Melis, T., Korman, J., and Kennedy, T. A. (2012). Abiotic \& biotic responses of the Colorado River to controlled floods at Glen Canyon Dam, Arizona, USA. River Research and Applications, 28(6):764-776.

Melis, T. S., Walters, C. J., and Korman, J. (2015). Surprise and opportunity for learning in Grand Canyon: the Glen Canyon Dam Adaptive Management Program. Ecology \& Society, 20(3):22.

Nelson, P. A., Bellugi, D., and Dietrich, W. E. (2014). Delineation of river bed-surface patches by clustering high-resolution spatial grain size data. Geomorphology, 205:102-119.

Nelson, P. A., Dietrich, W. E., and Venditti, J. G. (2010). Bed topography and the development of forced bed surface patches. Journal of Geophysical Research: Earth Surface, 115(F4).

Nelson, P. A., Venditti, J. G., Dietrich, W. E., Kirchner, J. W., Ikeda, H., Iseya, F., and Sklar, L. S. (2009). Response of bed surface patchiness to reductions in sediment supply. Journal of Geophysical Research: Earth Surface, 114(F2).

Perron, J. T., Kirchner, J. W., and Dietrich, W. E. (2008). Spectral signatures of characteristic spatial scales and nonfractal structure in landscapes. Journal of Geophysical Research Earth Surface, 113:F04003.

Quintino, V., Freitas, R., Mamede, R., Ricardo, F., Rodrigues, A. M., Mota, J., Pérez-Ruzafa, Á., and Marcos, C. (2009). Remote sensing of underwater vegetation using single-beam acoustics. ICES Journal of Marine Science, pages $594-605$.

Riegl, B. M., Moyer, R. P., Morris, L. J., Virnstein, R. W., and Purkis, S. J. (2005). Distribution and seasonal biomass of drift macroalgae in the Indian River Lagoon (Florida, USA) estimated with acoustic seafloor classification (QTCView, Echoplus). Journal of Experimental Marine Biology and Ecology, 326(1):89-104.

Rubin, D. M., Tate, G., Topping, D. J., and Anima, R. A. (2001). Use of rotating side-scan sonar to measure bedload. Proceedings of the Seventh Federal Interagency Sedimentation Conference, Reno, Nevada, 3:139-144.

Rubin, D.M., Chezar, H., Harney, J.N., Topping, D.J., Melis, T.S., and Sherwood, C.R. (2007). Underwater microscope for measuring spatial and temporal changes in bed-sediment grain size. Sedimentary Geology, 202(3):402-408.

Sabol, B. M., Eddie Melton, R., Chamberlain, R., Doering, P., and Haunert, K. (2002). Evaluation of a digital echo sounder system for detection of submersed aquatic vegetation. Estuaries and Coasts, 25(1):133-141.

Schimel, A. C. G., Beaudoin, J., Gaillot, A., Keith, G., Le Bas, T., Parnum, I., and Schmidt, V. (2015). Processing backscatter data: from datagrams to angular responses and mosaics. Marine Geological and Biological Habitat Mapping. A collective report by members of the GeoHab Backscatter Working Group, 200 pp. 
Schmidt, J. C. (1990). Recirculating flow and sedimentation in the Colorado River in Grand Canyon, Arizona. The Journal of Geology, 98(5):709-724.

Schwarz, G. (1978). Estimating the dimension of a model. The Annals of Statistics, 6(2):461464.

Shannon, J. P., Blinn, D. W., McKinney, T., Benenati, E. P., Wilson, K. P., and O'Brien, C. (2001). Aquatic food base response to the 1996 test flood below Glen Canyon Dam, Colorado River, Arizona. Ecological Applications, 11(3):672-685.

Simons, D. G. and Snellen, M. (2009). A Bayesian approach to seafloor classification using multi-beam echo-sounder backscatter data. Applied Acoustics, 70:1258-1268.

Thompson, R. (1979). Coherence significance levels. Journal of the Atmospheric Sciences, 36(10):2020-2021.

Topping, D. J., Rubin, D. M., Nelson, J. M., Kinzel, P. J., and Corson, I. C. (2000). Colorado river sediment transport: 2 . Systematic bed-elevation and grain-size effects of sand supply limitation. Water Resources Research, 36(2):543-570.

Van Rein, H., Brown, C., Quinn, R., Breen, J., and Schoeman, D. (2011). An evaluation of acoustic seabed classification techniques for marine biotope monitoring over broadscales $\left(>1 \mathrm{~km}^{2}\right)$ and meso-scales $\left(10 \mathrm{~m}^{2}-1 \mathrm{~km}^{2}\right)$. Estuarine, Coastal and Shelf Science, 93(4):336-349.

Welch, P. D. (1967). The use of fast Fourier transform for the estimation of power spectra: A method based on time averaging over short, modified periodograms. IEEE Transactions on Audio and Electroacoustics, 15(2):70-73.

Welton, B. (2014). A field method for backscatter calibration applied to NOAA's Reson 7125 multibeam echo-sounders. In Thesis (M.S.) University of New Hampshire, ProQuest, UMI Dissertations Publishing 1525648: 1-120.

Wilson, R. P. (1986). Sonar patterns of Colorado River bed, Grand Canyon. In Proceedings of the Fourth Federal Interagency Sedimentation Conference March 24-27, 1986, Las Vegas, Nevada., volume 2, pages 5-133-5-142.

Wright, S. A. and Kaplinski, M. (2011). Flow structures and sandbar dynamics in a canyon river during a controlled flood, Colorado River, Arizona. Journal of Geophysical Research - Earth Surface, 116:F01019. 
Table 1. GMM model parameters, and out-of-sample evaluation of sediment classification model skill.

\begin{tabular}{|l|c|c|c|c|c|c|c|}
\hline Class & Description & $\mu_{k}(\mathrm{~dB})$ & $\Sigma_{k}(\mathrm{~dB})$ & $w_{k}(-)$ & Precision & Recall & $F_{1}$ \\
\hline$S$ & sand & -141.91 & 55.44 & 0.53 & 1.00 & 0.95 & 0.98 \\
$S g$ & sand/gravel & -127.85 & 33.92 & 0.17 & 0.86 & 0.95 & 0.91 \\
$G$ & gravel & -114.64 & 37.38 & 0.14 & 0.95 & 1.00 & 0.97 \\
$s B R$ & sand/boulder/bedrock & -101.91 & 112.33 & 0.14 & 1.00 & 1.00 & 1.00 \\
$b R$ & boulder/bedrock & -46.45 & 144.56 & 0.002 & - & - & - \\
$U$ & unknown & -73.18 & 81.90 & 0.02 & - & - & - \\
\hline$V$ & dense veg. & -113.51 & 16.78 & 0.22 & 1.00 & 0.99 & 0.99 \\
$v S G$ & sparsely veg. sand/gravel & -104.16 & 11.95 & 0.36 & 0.94 & 1.00 & 0.97 \\
$v G$ & sparsely veg. gravel & -94.93 & 24.98 & 0.21 & - & - & - \\
$G c$ & unveg. coarse gravel/cobble & -79.50 & 183.19 & 0.20 & 1.00 & 0.53 & 0.70 \\
$c B R$ & unveg. cobble/boulder/bedrock & -31.91 & 51.06 & 0.001 & 0.68 & 1.00 & 0.81 \\
\hline
\end{tabular}

Table 2. Confusion matrices for unvegetated (top) and partially vegetated (bottom) sites.

\begin{tabular}{lcccc}
\hline & \multicolumn{4}{c}{$\%$ classified as ... } \\
\cline { 2 - 5 } Substrate & $S$ & $G$ & $s B R$ & $b R$ \\
\hline$S$ & 95.35 & 4.65 & 0 & 0 \\
$G$ & 0 & 95.26 & 4.74 & 0 \\
$s B R$ & 0 & 0 & 99.96 & 0.04 \\
$b R$ & 0 & 0 & 0 & 100 \\
\hline
\end{tabular}

\begin{tabular}{lccccc}
\hline & & \multicolumn{4}{c}{$\%$ classified as ... } \\
\cline { 3 - 6 } Substrate & & $V$ & $v S G$ & $G c$ & $c B R$ \\
\cline { 3 - 6 }$V$ & & 91.62 & 8.38 & 0 & 0 \\
$v S G$ & & 0 & 100 & 0 & 0 \\
$G c$ & & 0 & 19 & 51.43 & 29.67 \\
$c B R$ & & 0.18 & 0 & 0 & 99.82 \\
\hline
\end{tabular}




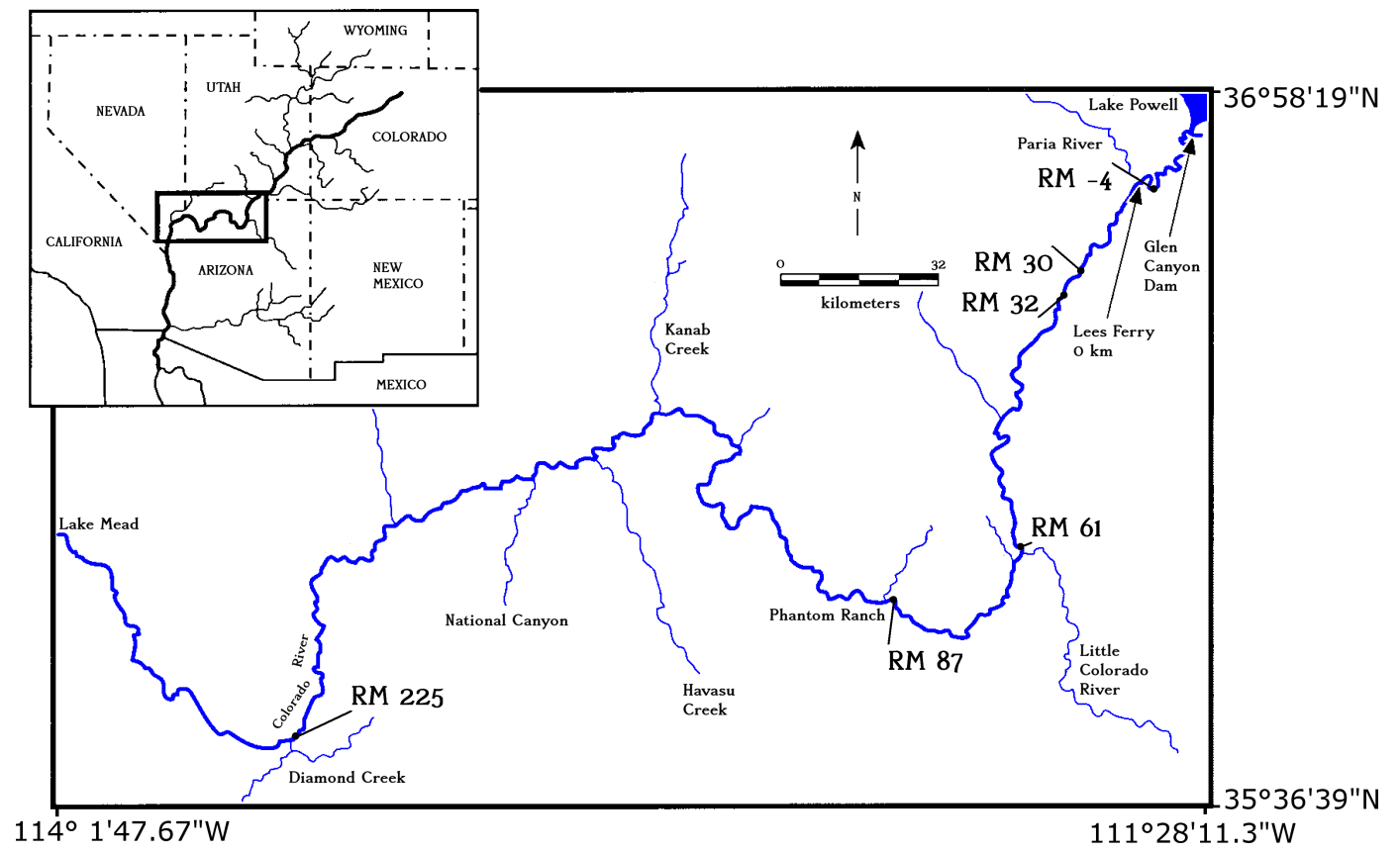

Figure 1. Locations of the six study sites (prefixed with 'RM' which stands for river mile) along the Colorado River in Glen, Marble and Grand Canyons. 


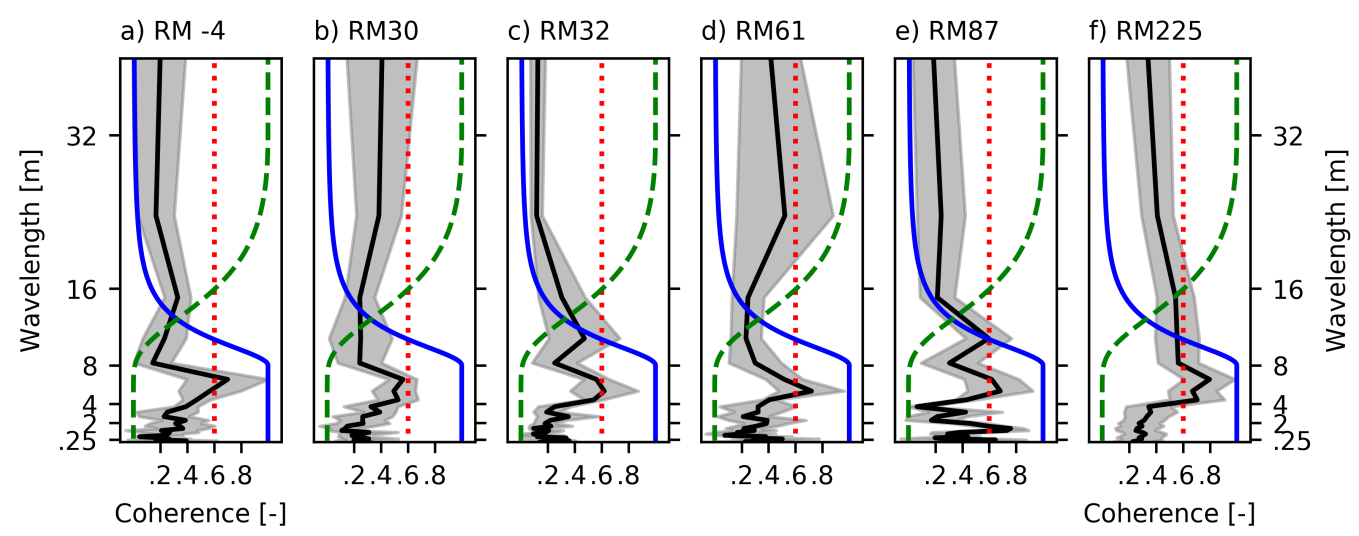

Figure 2. Mean coherence spectra between topography and backscatter at each of the six study sites shown in Figure 1. The black lines show the coherence between topography and backscatter as a function of wavelength in meters. The blue solid, green dashed and red dotted lines are, respectively, the high-pass filter function, low-pass filter function and significance threshold (see text for details). The grey envelope in each plot represents the range of co-spectral densities observed at that site. 


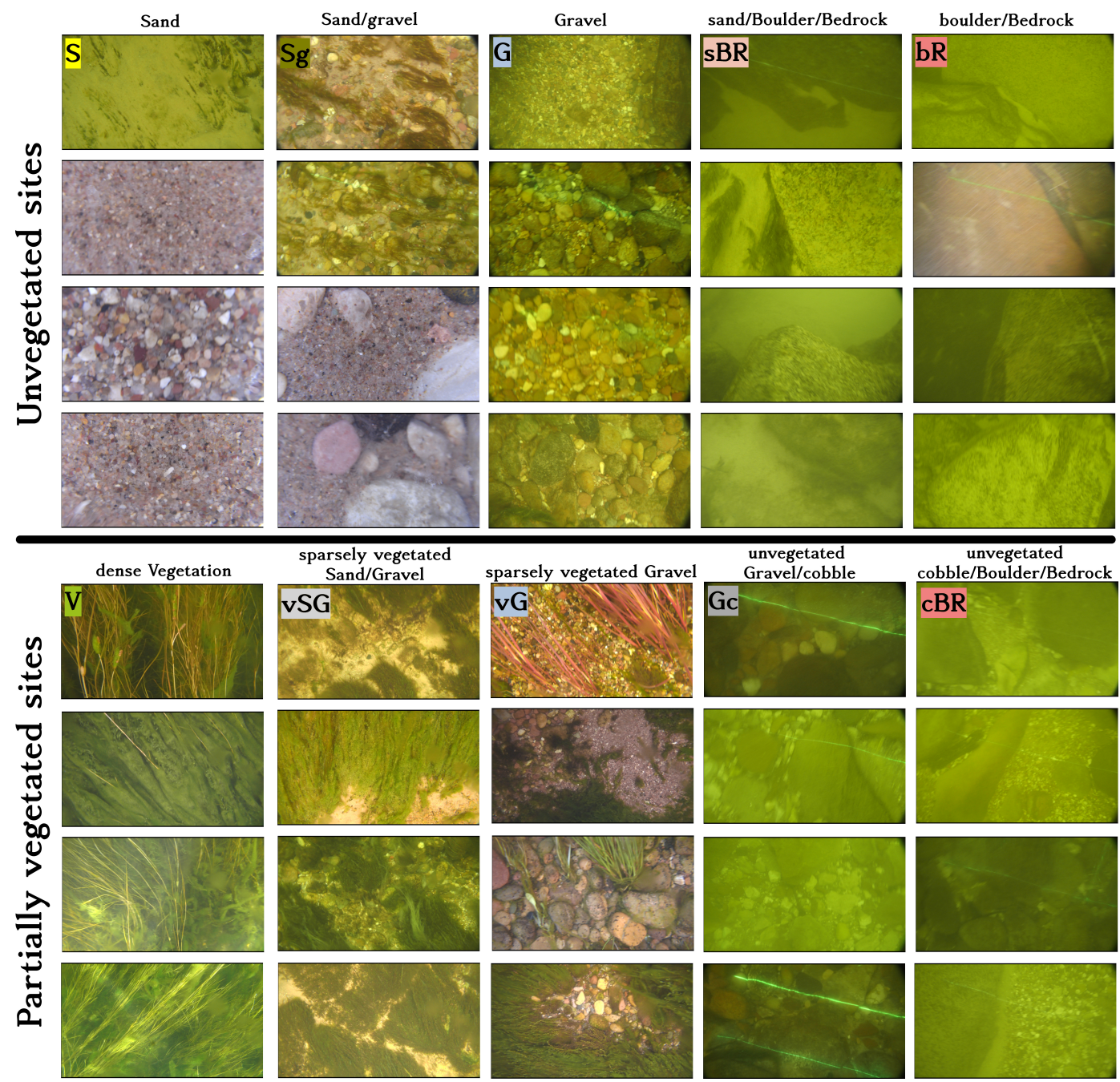

Figure 3. Example imagery for each of 10 unique substrate classes easily identifiable by eye, arranged in two groups of five. The first group are found in sites where the riverbed is completely unvegetated (top four rows). The second group (bottom four rows) are found in partially vegetated riverbeds. The substrate codes shown in the first image in every group are those defined in Table 1 and colored the same as how they are represented in Figure 6. 

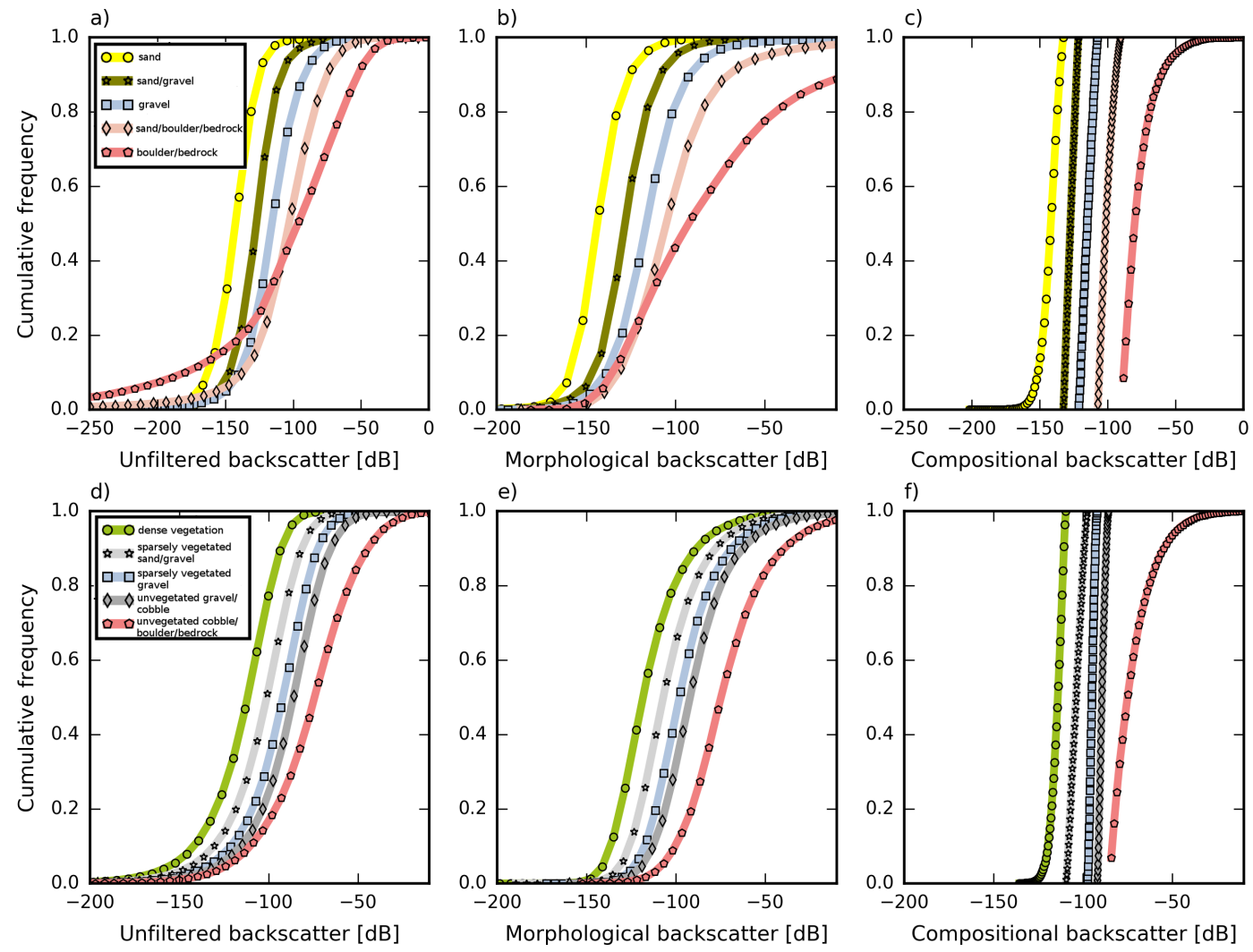

Figure 4. Low-pass filtering greatly enhances the discriminatory power of backscatter among categorical substrate types, observed using underwater video data: a) per-substrate unfiltered backscatter distributions from the training data set aggregated over all five unvegetated study sites; equivalent morphological (b) and compositional (c) backscatter distributions; d) per-substrate unfiltered backscatter distributions from the training data set aggregated over the partially vegetated study site; equivalent morphological (e) and compositional (f) backscatter distributions. 
a) Depth

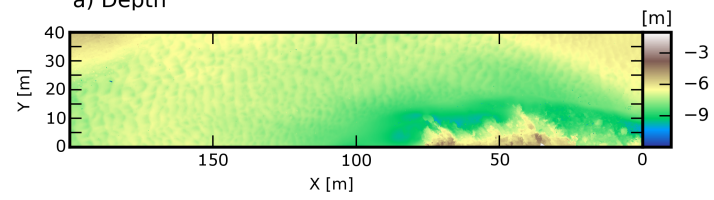

b) Backscatter

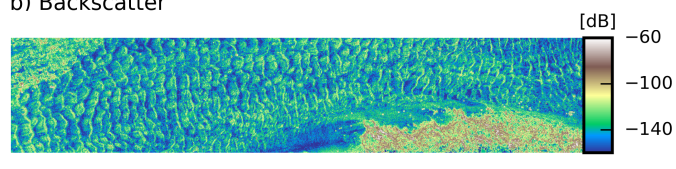

c) Morphological Backscatter

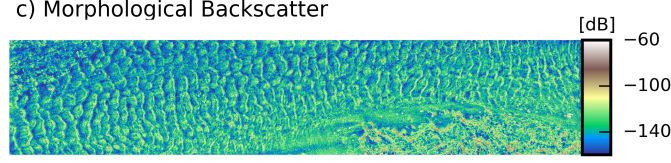

d) Compositional Backscatter

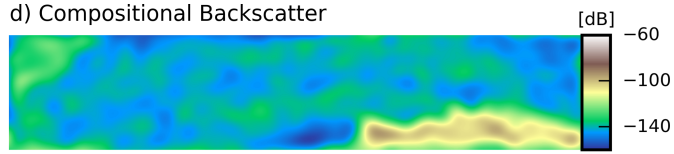

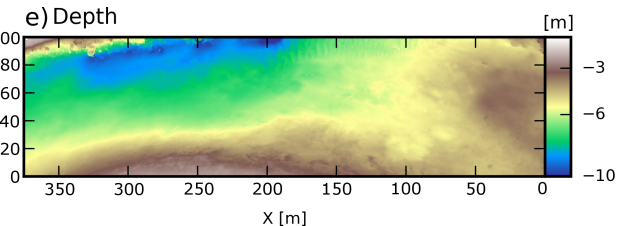
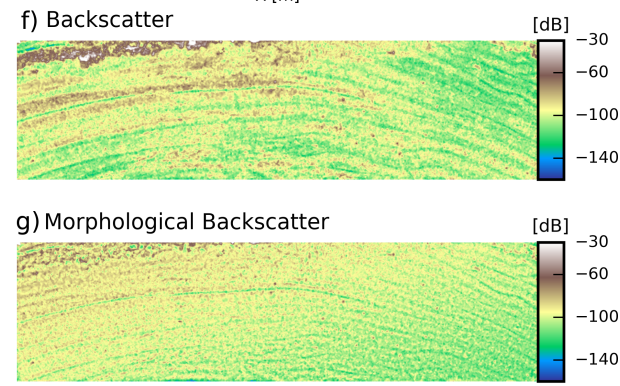

h) Compositional Backscatter

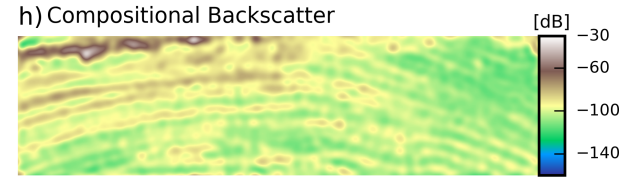

Figure 5. Example backscatter decomposition over a small $(200 \times 40 \mathrm{~m})$ subset of unvegetated reach (at RM87) dominated by low-amplitude sand dunes: a) bathymetry; b) unfiltered backscatter; c) morphological backscatter; and d) compositional backscatter. Panels e through h show the same quantities over a $375 \times 100$ $\mathrm{m}$ subset of the partially vegetated reach at RM -4 . All data on a regular $25 \mathrm{~cm}$ grid. 

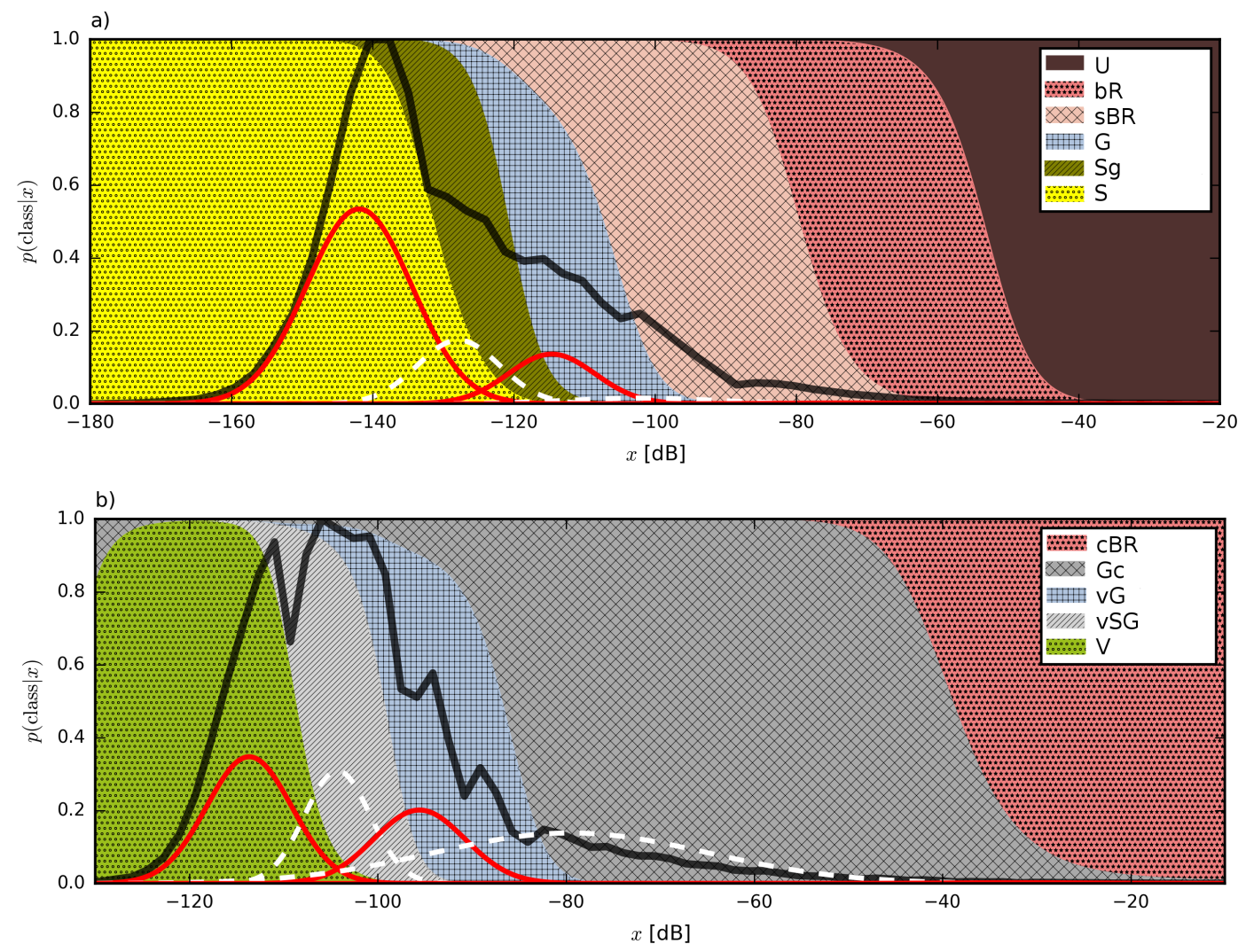

Figure 6. Probabilistic model for predicting substrate type: a) decision surface for the unvegetated substrate model based on six substrates, showing component Gaussian probability density functions (dashed white and solid red lines) and a typical distribution of measured compositional backscatter from the riverbed (dark line) and b) equivalent decision surface for the partially vegetated substrate model based on five substrates. See Table 1 for substrate codes. Note that not all component distributions (solid red and dashed white lines) are visible owing to very small values of $w_{k}$ (Table 1 ).

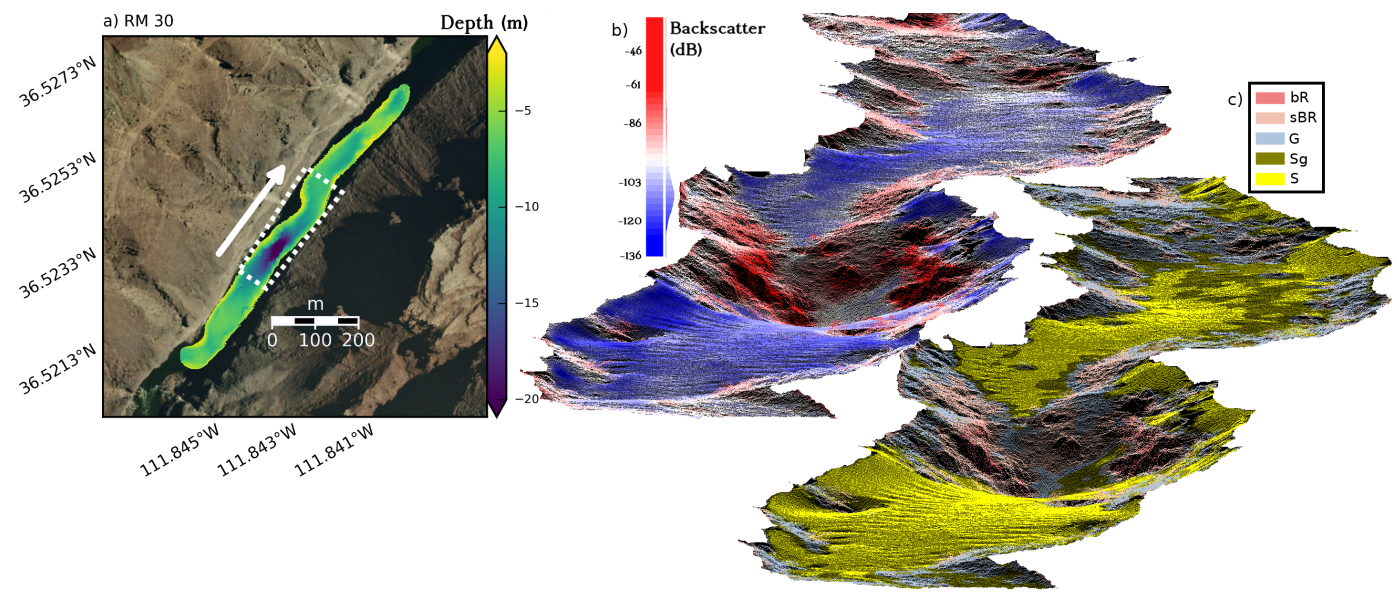

Figure 7. a) Bathymetry and aerial image of RM 30; b) three-dimensional perspective view of a point cloud, at $25 \mathrm{~cm}$ grid resolution, of compositional backscatter values within the area denoted in panel a) by the white box, in the direction of the arrow looking upstream; c) point cloud of corresponding sediment classes from a five-class GMM model. See Table 1 for substrate codes. 

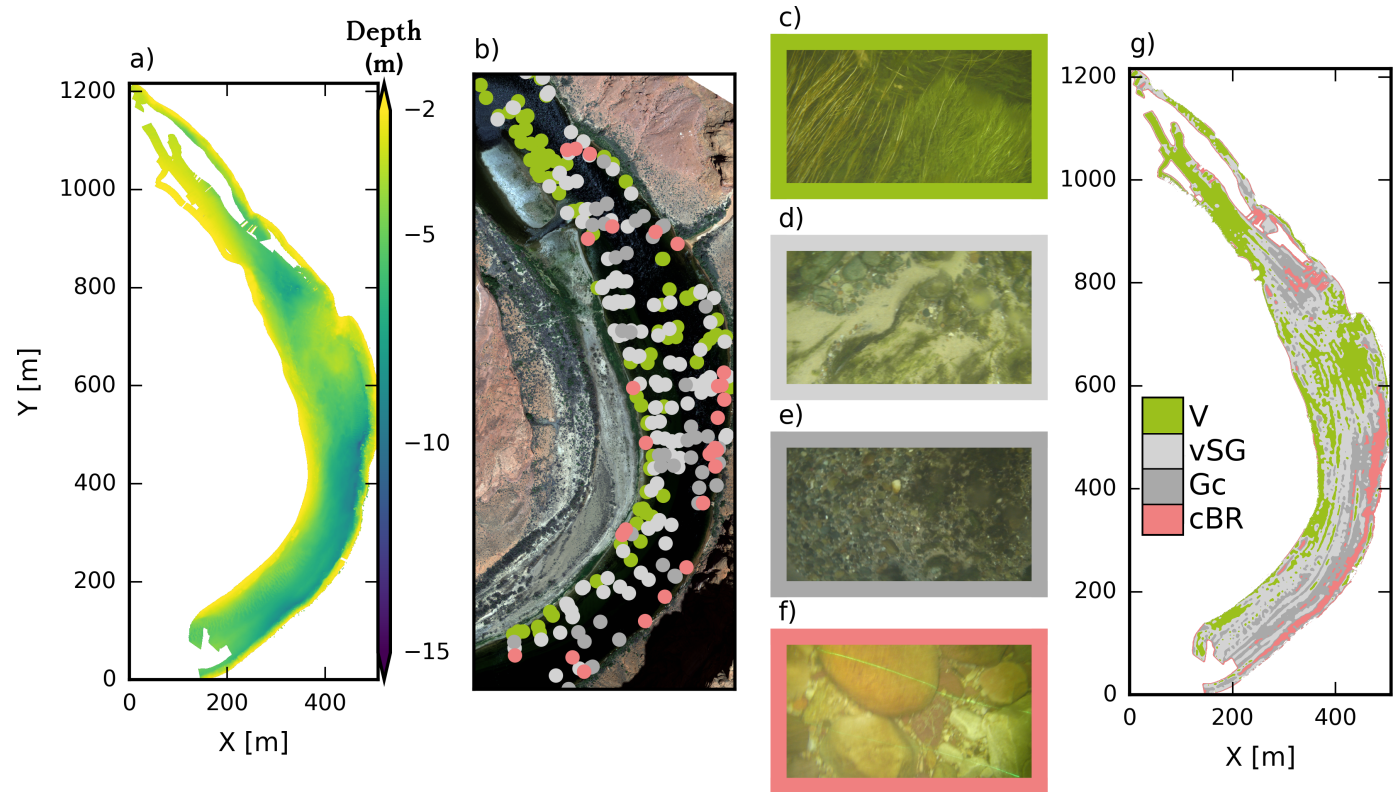

Figure 8. a) Bathymetry of RM -4; b) aerial image with color-coded markers showing video observations of substrates in 4 categories exemplified by the images in the panels (c to f, see Table 1 for substrate codes); and $\mathrm{g}$ ) four-class substrate map produced using the model in Figure $6 \mathrm{~b}$ using the compositional backscatter at $25 \mathrm{~cm}$ resolution.
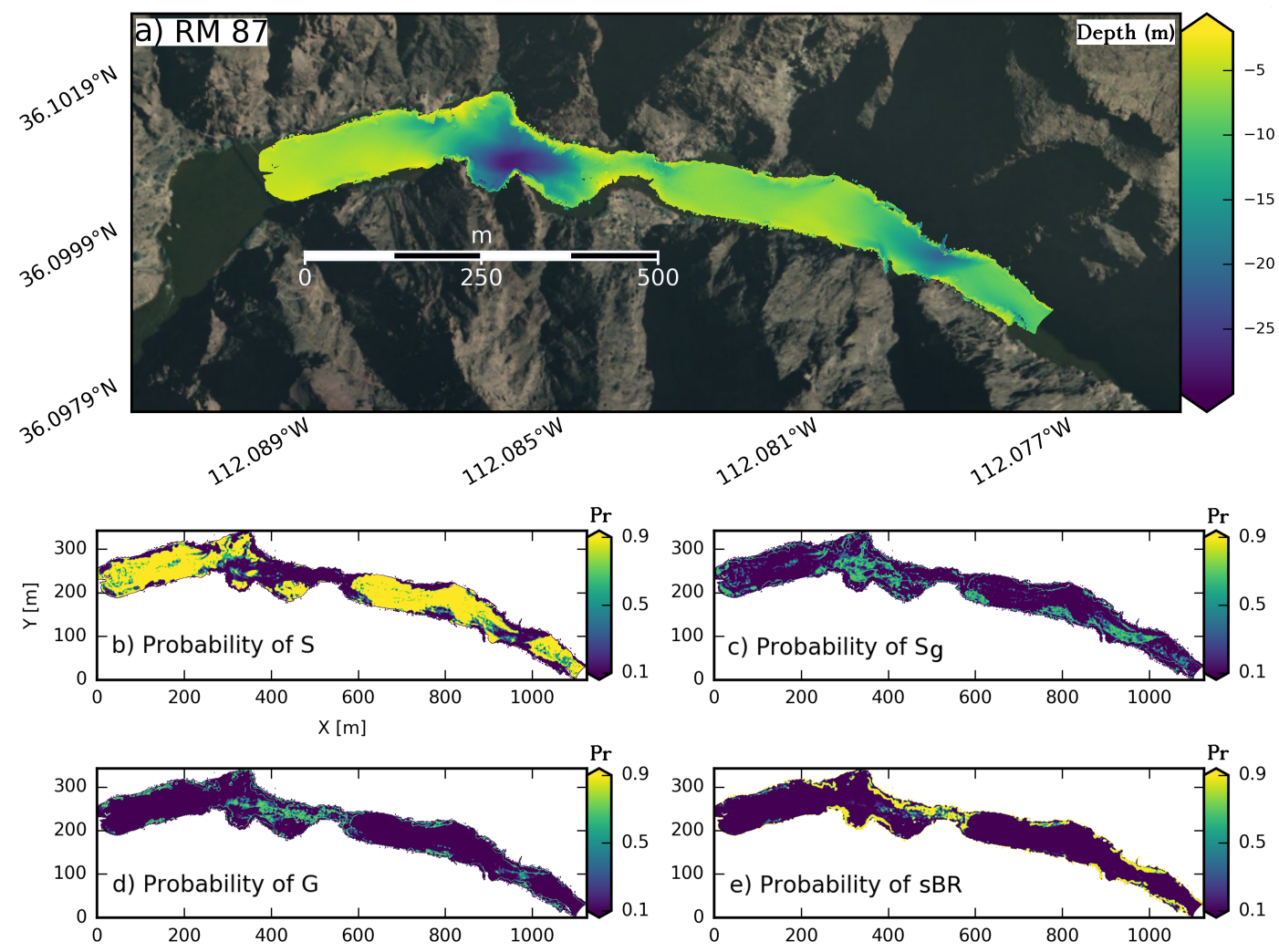

Figure 9. a) Bathymetry at $25 \mathrm{~cm}$ grid resolution and aerial image of the RM 87 site, b) through e) GMMderived posterior probabilities for 4 substrate classes, all at $25 \mathrm{~cm}$ grid resolution. See Table 1 for substrate codes. 

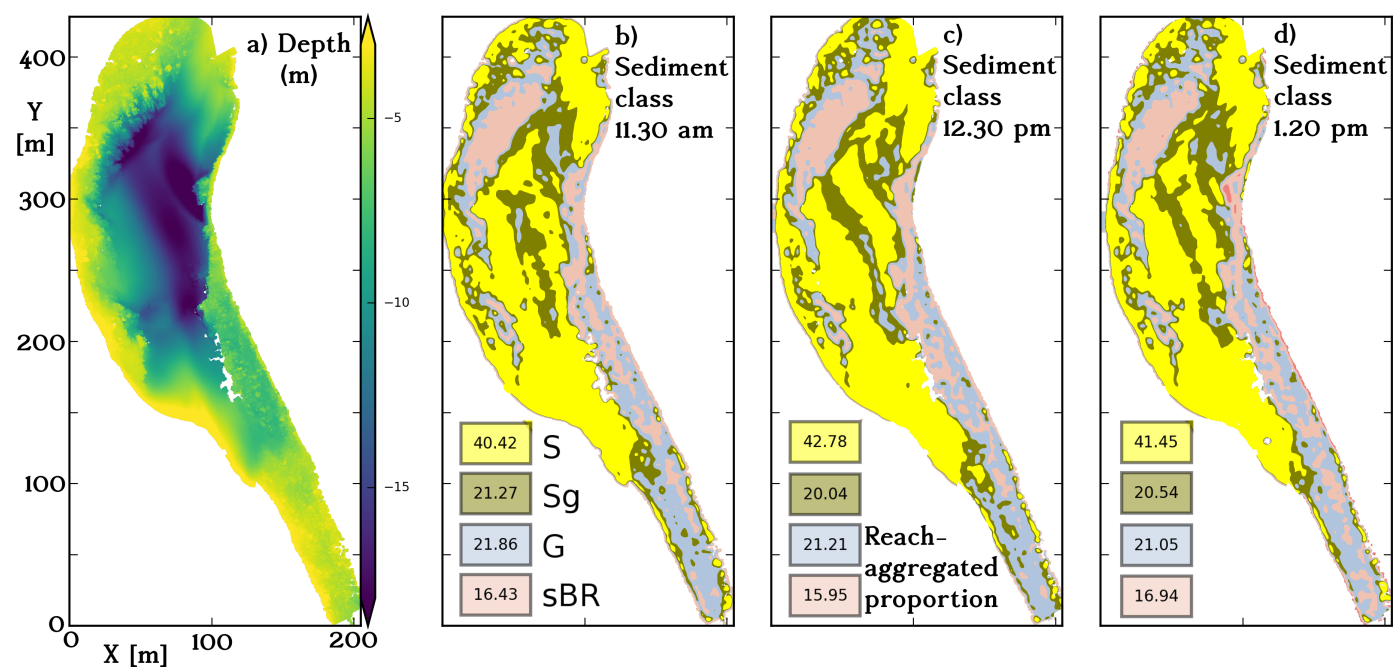

b) Transition probabilities

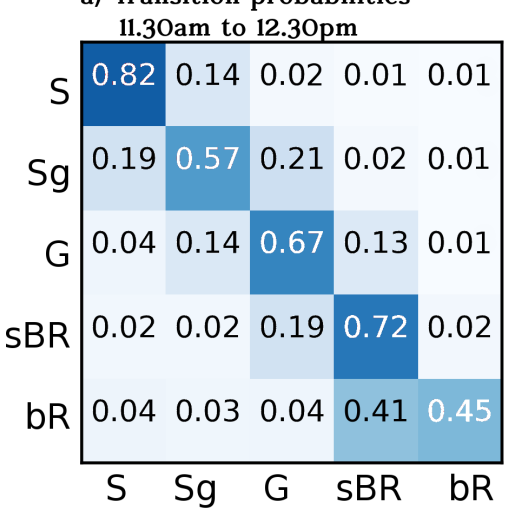

Figure 10. a) bathymetry; b) through d), a time-series sediment classification maps of the RM 32 site from three surveys conducted over two hours (respective titles indicate time of day). See Table 1 for substrate codes.
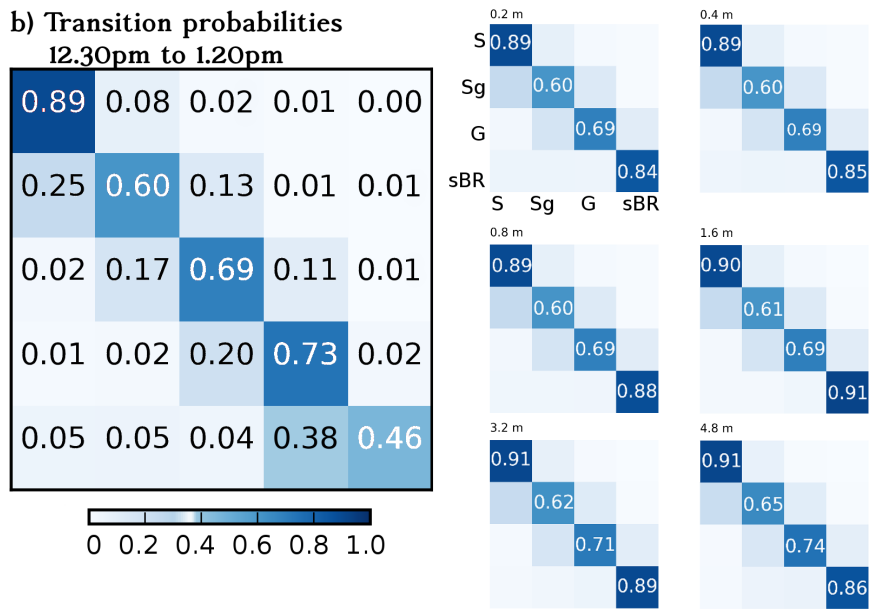

Figure 11. Evaluating the precision of the unvegetated sediment classification through an analysis of transition between per-pixel substrate classes: panels a and b, matrices of survey-to-survey (respective titles indicate time of day) transition probabilities between each of five-substrate classes at $10 \mathrm{~cm}$ resolution. See Table 1 for substrate codes. Right panel, matrices of survey-to-survey transition probabilities between each of 4 substrate classes at increasing resolution from $20 \mathrm{~cm}$ to $4.8 \mathrm{~m}$, showing how the precision of sediment classifications increase with aggregation of scale. 

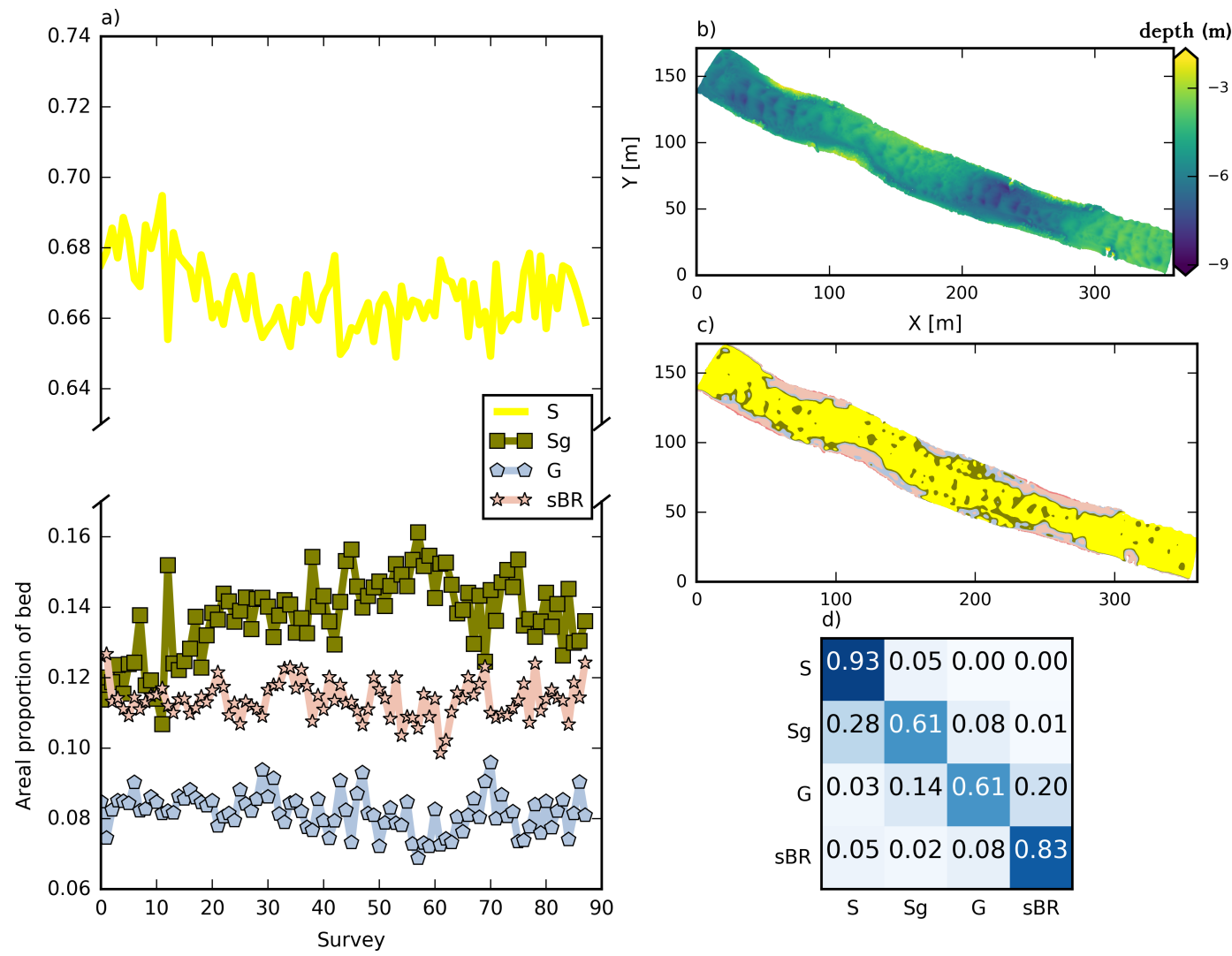

Figure 12. Data from substrate maps constructed from 88 surveys of the same reach at the RM 225 site, every $\sim 10$ minutes over 13 hours: a) time-series of areal proportions of four substrate types; b) bathymetry; c) example bed sediment classification from one of the surveys. Colors correspond with sediment types defined in (a); d) matrix of survey-to-survey transition probabilities. See Table 1 for substrate codes. 

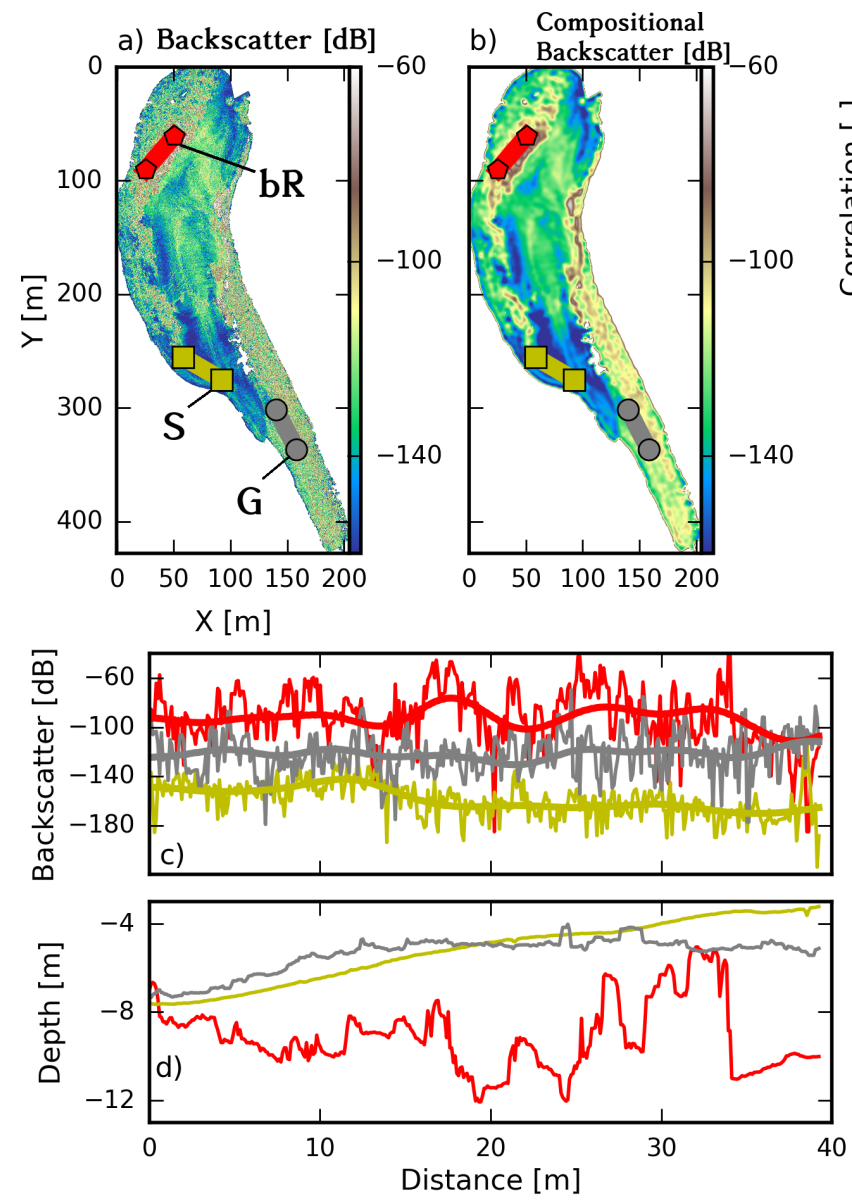
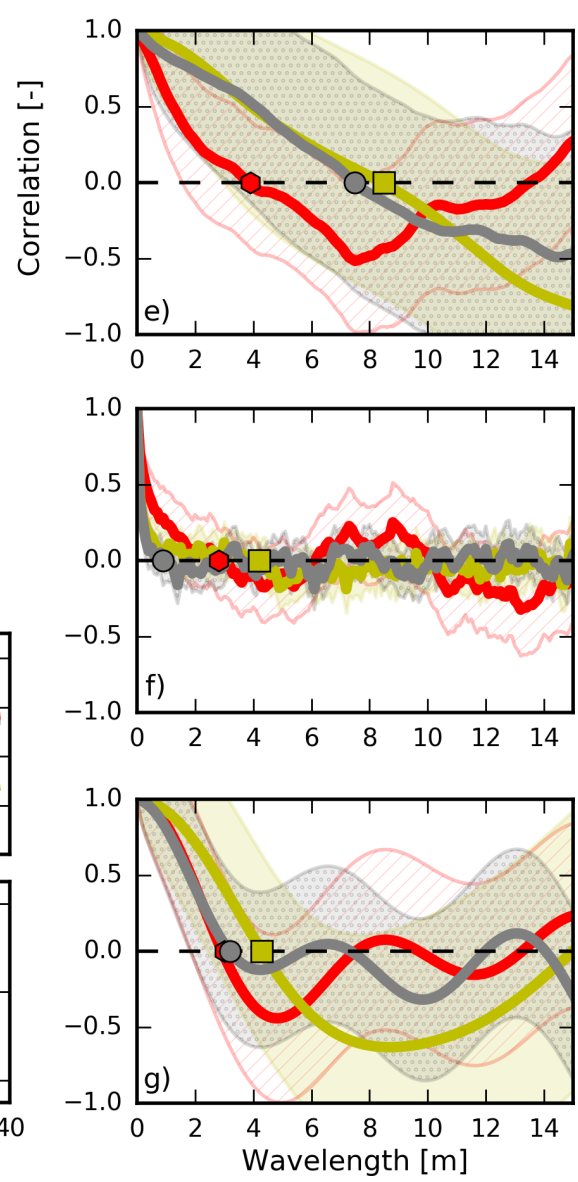

Figure 13. Unfiltered (a) and compositional (b) backscatter at the RM 32 site; c) example 1D traces of backscatter through an area of three different substrates (see Table 1 for substrate codes), where the smoother lines are the compositional backscatter with the high frequency component due to topography removed. Locations of these substrate transects are shown in (a); d) the corresponding bed depth through the three traces in (c); e) the typical autocorrelation function of topography per substrate (the line shows the autocorrelation for the transects in a) whereas the envelope shows the variability for the entire site, markers show the intersection with zero) as a function of wavelength; the corresponding autocorrelation function of unfiltered (f) and compositional (g) backscatter. 


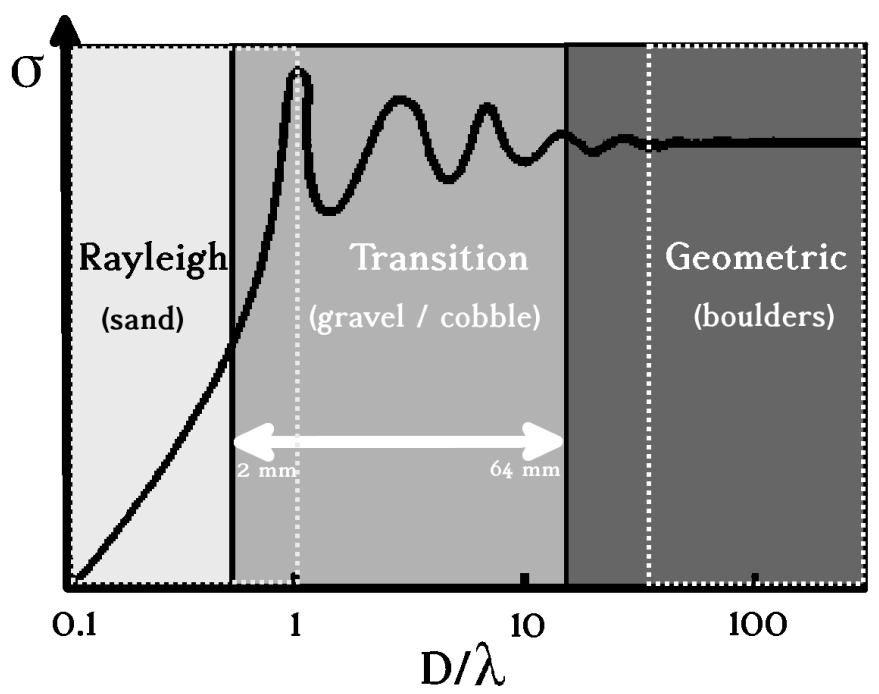

Figure 14. Schematic of backscattering regimes for a $400 \mathrm{kHz}$ system in freshwater with a speed of sound of $1475 \mathrm{~ms}^{-1}$ (acoustic wavelength $\lambda=3.68 \mathrm{~mm}$ ), in terms of scattering cross section form function, $\sigma$ (dimensionless). Grain size $(D)$ for gravel is transitional between Rayleigh (sand) and geometric (boulders) acoustic regimes, indicated by the dashed boxes. 